EDUARDO GUALTIERI DE ANDRADE PEREZ

Efeito do tratamento antioxidante sistêmico e em amostras espermáticas de touros Bos taurus taurus submetidos ao estresse térmico e suplementados com dieta rica em ácidos graxos poliinsaturados

São Paulo 


\section{Efeito do tratamento antioxidante sistêmico e em amostras espermáticas de touros Bos taurus taurus submetidos ao estresse térmico e suplementados com dieta rica em ácidos graxos poliinsaturados}

Tese apresentada ao Programa de PósGraduação em Reprodução Animal da Faculdade de Medicina Veterinária e Zootecnia da Universidade de São Paulo para a obtenção do Título de Doutor em Ciências

Departamento:

Reprodução Animal

Área de Concentração:

Reprodução Animal

Orientador:

Profa. Dra. Valquiria Hyppolito Barnabe

São Paulo

2014

Ficha Catalográfica 
Autorizo a reprodução parcial ou total desta obra, para fins acadêmicos, desde que citada a fonte.

\section{DADOS INTERNACIONAIS DE CATALOGAÇÃO-NA-PUBLICAÇÃO}

(Biblioteca Virginie Buff D’Ápice da Faculdade de Medicina Veterinária e Zootecnia da Universidade de São Paulo)

Perez, Eduardo Gualtieri de Andrade

Efeito do tratamento antioxidante sistêmico e em amostras espermáticas de touros Bos taurus taurus submetidos ao estresse térmico e suplementados com dieta rica em ácidos graxos poliinsaturados / Eduardo Gualtieri de Andrade Perez. -- 2014 52 f. : il.

Tese (Doutorado) - Universidade de São Paulo. Faculdade de Medicina Veterinária e Zootecnia. Departamento de Reprodução Animal, São Paulo, 2014.

Programa de Pós-Graduação: Reprodução Animal.

Área de concentração: Reprodução Animal.

Orientador: Profa. Dra. Valquíria Hyppolito Barnabe.

1. Sêmen. 2. Touros Bos Taurus taurus. 3. Estresse oxidativo. 4. Vitamina E. 5. Ácidos graxos poliinsaturados. I. Título. 


\section{PARECER}

\section{Interessado: Eduardo Gualtieri de Andrade Perez}

\section{Assunto: Protocolo de experimentação adotado em experimento animal}

A Comissão de Ética no uso de animais da Faculdade de Medicina Vetérinária e Zootecnia da Universidade de São Paulo analisou o projeto intitulado: "Efeito do tratamento antioxidante sistêmico e em amostras espermáticas de touros Bos taurus taurus submetidos ao estresse térmico e suplementados com dieta rica em ácidos graxos poliinsaturados", protocolado sob o número 1681/2009, utilizando 16 (dezesseis) touros, sob a responsabilidade da Profa. Dra. Valquiria Hyppolito Barnabe, e constatou que o mesmo foi realizado de acordo com os princípios de ética adotados por esta Comissão.

The "Ethic Committee in the use of animals" of the School of Veterinary Medicine and Animal Science of University of São Paulo has analyzed the research entitled: "Effect of systemic and sperm samples treatment with antioxidants from bulls Bos taurus taurus under heat stress and supplemented with diet rich in poly-unsaturated fatty acids", protocol number 1681/2009, under the responsibility Profa. Dra. Valquiria Hyppolito Barnabe, and found that it was conducted in accordance with the principles of ethics adopted by the committee.

São Paulo, 9 de abril de 2012.

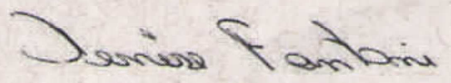

Denise Tabacchi Fantoni

Presidente 


\section{FOLHA DE AVALIAÇÃO}

Nome: PEREZ, Eduardo Gualtieri de Andrade

Título: Efeito do tratamento antioxidante sistêmico e em amostras espermáticas de touros Bos taurus taurus submetidos ao estresse térmico e suplementados com dieta rica em ácidos graxos poliinsaturados

Tese apresentada ao Programa de Pós-Graduação em Reprodução Animal da Faculdade de Medicina Veterinária e Zootecnia da Universidade de São Paulo para a obtenção do Título de Doutor em Ciências

DATA

Banca Examinadora

Prof. Dr.

Instituição:

Julgamento:

Prof. Dr.

Instituição:

Julgamento:

Prof. Dr.

Instituição:

Julgamento:

Prof. Dr.

Instituição:

Julgamento:

Prof. Dr.

Instituição:

Julgamento: 


\section{Dedicatória}

Dedico primeiramente à Deus por seu incondicional apoio.

Dedidico este trabalho à memória de meu orientador de mestrado Professor Doutor Renato Campanarut Barnabe.

Também dedico aos meus avós Irineu Gualtieri e Célia Juliano Gualtier,i que estiveram muito doentes, por seu imenso amor. 


\section{Agradecimentos}

Agradeço à Deus por colocar pessoas tão boas em meu caminho.

Sempre fui uma pessoa muito feliz por possuir tantos amigos que me ajudaram em cada momento de minha vida. Até mesmo quando estive pronto para desistir e encarar o chão os braços amigos impediram-me de cair.

Marcílio Nichi, meu grande amigo, sempre me apoiou em todas etapas da pós-graduação. Sinto que minhas palavras não serão capazes de expressar minha gratidão por sua ajuda e amizade incondicional. Mesmo quando eu joguei a toalha e fugi, você teve a sensibilidade de sublimar que eu passava por um período difícil, injetar auto-estima e ânimo. Muito obrigado!

João Diego Losano, desde quando veio estagiar no $L A$ eu me identifiquei muito com você. Acredito que você seja uma das pessoas que Deus colocou em minha vida. Sempre foi um grande companheiro, dentro e fora da universidade, durante o experimento e confecção da tese. Os meus mais sinceros agradecimentos por tudo que fez por mim. Valeu mesmo irmão!

À minha orientadora Professora Doutora Valquíria Hyppolito Barnabe, por sempre ter me dado muito apoio, momentos de aprendizado e cultura. Jamais esquecerei o que a senhora fez por mim mesmo eu não tendo sido um orientado que faz jús à orientadora. Que Deus abençoe muito a senhora e que seus atos de bondade sejam derramados por Ele em dobro. Muito obrigado.

Agradeço à toda equipe do Laboratorio de Andrologia: Andressa Dalmazo, Carolina Camargo Rocha, Roberta H.Tsunoda, João Rafael Chinait Gurgel, Paola Almeida de Araújo Góes por inúmeros momentos agradáveis em bancada, fazenda, canil ou congresso. Agradeço ainda por toda ajuda com minhas amostras.

Miguel muito obrigado pela ajuda com minhas amostras. Camila meu muito obrigado pelas amostras de SCSA.

Agradeço ao Professor Doutor Carlos Henrique Cabral Viana por ter me iniciado na pós-graduação, ter acompanhado de perto a minha caminhada e participado de todoas as bancas da minha vida. Muito Obrigado! conferida.

Agradeço à Pós Graduação em Reprodução Animal pela formação

Agradeço à FMVZ USP pela possibilidade de estudar nesta magnífica instituição.

Agradeço às secretárias do departamento e pós graduação: Thais, Roberta e Harumi respectivamente.

Agradeço aos meus avós Irineu e Célia Gualtieri por viabilizarem meu projeto de doutorado em sua propriedade rural, pelo apartamento que moro, pelas viagens internacionais à congressos, pelo meu Laboratório, pelo amor indondicional, apoio emocional, por existirem. Amo vocês. Muito obrigado!

Agradeço ao meu pai Dr. Sergio de Andrade Perez por seu apoio, amizade e resgate da nossa família. Te amo pai!

Agradeço à minha mãe por ter sido meu porto seguro durante a pior depressão dos meus dias. Se existo, é devido à você. Te amo.

Paty, minha querida irmã, sabe que eu te amo demais? Guess everybody knows. Valeu mesmo por todas puxadas de orelha.

Kiki, minha cunhada do coração, obrigado por todo seu carinho.

Agradeço à toda minha família por ser o referencial da minha existência! 
Agradeço ao meu amigo e sócio Bernardo Augusto França Dias de Oliveira por todo seu apoio, reflexões e empenho para que eu seja um ser humano melhor. Valeu amigo!

Ah, o que falar para meu amigo do peito Flávio Giovani Pelegrini (Soneca), cara, muito obrigado por tudo, desde sempre.

Agradeço ao Laboratório de Andrologia por toda execução de meu doutorado e inerente aprendizado.

Agradeço à CRV Lagoa da Serra pelas amostras cedidas para trabalhos apresentados em eventos internacionais.

Agradeço ao Professor Doutor Sylvio Goulart Rosa Jr. por todo seu apoio no ParqTec e Sebrae.

Agradeço à CAPES pela bolsa de estudos.

Agradeço à Fapesp por auxílio financeiro ao nossos projetos e aquisição do CASA.

Agradeço à senhora Elza Fachin pela presteza na correção da tese.

Agradeço à todos que me ajudaram ou foram importantes para mim e minha tese que acabei por esquecer... Eu realmente fiz estes muito obrigados no último momento!!! 


\section{EPÍGRAFE \\ Through the rain}

When you get caught in the rain

With nowhere to run

When you're distraught

And in pain without anyone

When you keep crying out to be saved

But nobody comes

And you feel so far away

That you just can't find your way home

You can get there alone, it's ok

Once you say

\section{CHORUS:}

I can make it through the rain

I can stand up once again

On my own and I know

That I'm strong enough to mend

And every time I feel afraid

I hold tight to my faith

And I live one more day

And I make it through the rain

And if you keep falling down

Don't you dare give in

You will arise safe and sound

So keep pressing on steadfastly

And you'll find what you need to prevail

Once you say

\section{CHORUS}

And when the wind blows

And shadows grow close

Don't be afraid

There's nothing you can't face

And should they tell you

You'll never pull through

Don't hesitate

Stand tall and say

\section{CHORUS}

And I'll live one more day, and I

I can make it through the rain

Oh yes you can

You're gonna make it through the rain

\section{Carey Mariah; Affanasief Walter}




\section{RESUMO}

PEREZ, E. G. A. Efeito do tratamento antioxidante sistêmico e em amostras espermáticas de touros Bos taurus taurus submetidos ao estresse térmico e suplementados com dieta rica em ácidos graxos poliinsaturados. [Effect of systemic antioxidant treatment in Bos taurus taurus bulls under heat stress and supplemented with polyunsaturated fatty acids]. 2013. 52 f. Tese (Doutorado em Ciências) - Faculdade de Medicina Veterinária e Zootecnia, Universidade de São Paulo, São Paulo, 2014.

Uma das razões da menor fertilidade dos touros europeus criados em regiões tropicais em relação a touros Bos indicus é uma maior índice de estresse oxidativo provocado por uma maior produção de espécies reativas de oxigênio (ROS), não compensada pela proteção antioxidante. Por outro lado, sabe-se que a célula espermática é extremamente susceptível ao estresse oxidativo devido à alta quantidade de ácidos graxos poli-insaturados (PUFA) em sua membrana plasmática, o que, no entanto, é muito importante para que o espermatozoide seja fértil e resistente ao choque frio. Sendo assim, tratamentos que interfiram no processo oxidativo, podem ser importantes para aumentar a produtividade destes animais, tanto à campo como em centrais de inseminação artificial. O presente experimento objetivou avaliar qual ROS seria a mais lesiva para touros europeus submetidos ao estresse térmico visando determinar um possível tratamento antioxidante direcionado para estes animais. Em um segundo momento visou então verificar a eficiência da interação entre uma dieta rica em PUFAs e o tratamento antioxidante sistêmico direcionado na qualidade espermática do sêmen ejaculado e epididimário (fresco e criopreservado) de touros europeus submetidos ao estresse térmico. Para isso, quatro touros Bos taurus adultos foram submetidos a insulação testicular (bolsa escrotal por 5 dias). Sessenta dias após a insulação o sêmen foi coletado por eletroejaculação. O sêmen de cada animal foi dividido em 4 alíquotas s submetidas à indução com quatro sistemas geradores de ROS: Ânion Superóxido (xantina/xantina oxidase), peróxido de hidrogênio, radical hidroxila (Ascorbato + Sulfato de Ferro) e malondialdeído (MDA; produto da peroxidação lipídica). As amostras foram incubadas por 1 hora e avaliadas através da análise espermática computadorizada (CASA), eoxina/nigrosina (integridade da membrana plasmática), fast-green/rosa bengala (integridade de acrossomo), 3, 3' diaminobenzidina (atividade mitocondrial), ensaio da 
cromatina espermática (fragmentação de DNA) e substâncias reativas ao ácido tiobarbitúrico (TBARS; peroxidação lipídica). Os resultados indicaram ser o MDA, a substância mais deletéria aos animais Bos taurus submetidos ao estresse térmico aguda. Desta forma, 16 touros foram então submetidos á insulação testicular e divididos em 4 grupos: Controle ( $n=4$; aplicação de óleo mineral; placebo); Grupo Vitamina E: $\left(n=4 ; 5 \mathrm{ml}\right.$ de Monovin ${ }^{\circledR}$ E a cada 13 dias); Grupo PUFA: ( $n=4 ; 4$ kg/dia Megalac $\circledast$ E1), Grupo PUFA+Vitamina E: $(n=4$; combinação entre os tratamentos dos grupos PUFA e Vitamina E). O sêmen destes animais foi coletado no dia da inserção da bolsa escrotal, no dia da retirada, 30 e 60 dias após. Os resultados indicaram que a vitamina E foi eficiente para a melhora nos danos causados pelo estresse térmico no DNA espermático e na mitocôndria, mas apenas nas amostras coletadas do epidídidmo. Da mesma forma, foi possível observar que a combinação entre a Vitamina $E$ e a suplementação com PUFA foi eficiente na melhora dos padrões de motilidade espermática. Os resultados do presente estudo indicam que a combinação entre um tratamento antioxidante com Vitamina $E$ e a suplementação com PUFA pode ser uma alternativa interessante para evitar os danos causados pelo estresse térmico agudo em touros europeus. No entanto, possivelmente este tratamento poderia ser ainda mais eficiente caso seja administrado de forma preventiva.

Palavras-chave: Sêmen. Touros Bos Taurus taurus. Estresse oxidativo. Vitamina E. Ácidos graxos poliinsaturados. 


\section{ABSTRACT}

PEREZ, E. G. A. Effect of systemic antioxidant treatment in Bos taurus taurus bulls under heat stress and supplemented with polyunsaturated fatty acids. [Efeito do tratamento antioxidante sistêmico e em amostras espermáticas de touros Bos taurus taurus submetidos ao estresse térmico e suplementados com dieta rica em ácidos graxos poliinsaturados]. 2013. $52 \mathrm{f}$. Tese (Doutorado em Ciências) - Faculdade de Medicina Veterinária e Zootecnia, Universidade de São Paulo, São Paulo, 2014.

One reason for the lower fertility of European bulls bred in tropical regions is a higher rate of oxidative stress caused by increased production of reactive oxygen species (ROS) not compensated by antioxidant protection. On the other hand, it is known that the sperm cell is extremely susceptible to oxidative stress due to the high amount of polyunsaturated ( PUFA) on their plasma membrane. However the presence of these PUFAs is fundamental for the sperm to be fertile and resistant to cold shock. Thus, treatments that interfere with the oxidation process may be important to increase the productivity of these animals. This study aimed to evaluate which would be the most damaging ROS for European bulls subjected to heat stress to determine a possible antioxidant targeted treatment for these animals. In a second step we sought to verify the efficiency of the interaction between a diet rich in PUFAs and targeted-antioxidant treatment on sperm quality of ejaculated and epididymal sperm quality in European bulls subjected to heat stress. Four Bos taurus bulls were submitted to testicular insulation (5 days). Sixty days after insulation semen was collected by electroejaculation. Semen from each animal was divided into 4 aliquots and submitted to the induction with four ROS generating systems: superoxide anion (xanthine / xanthine oxidase), hydrogen peroxide, hydroxyl radical (ascorbate + Ferrous Sulfate) and malondialdehyde (MDA; lipid peroxidation product). The samples were incubated for $1 \mathrm{~h}$ and assessed by computerized sperm analysis (CASA), eoxina / nigrosin (membrane integrity), fast-green/Bengal rose (acrosome integrity) , 3 , 3 ' diaminobenzidine (mitochondrial activity), sperm chromatin structure assay (DNA fragmentation) and thiobarbituric acid reactive substances (TBARS, lipid peroxidation). The results indicated that the MDA was the most deleterious substance to Bos taurus semen subjected to an acute heat stress. Thus, 16 bulls were then subjected to testicular insulation and divided into 4 groups: control $(n=4$; 
application of mineral oil; placebo); Group Vitamin E: $\left(n=4,5 \mathrm{ml}\right.$ of Monovin ${ }^{\circledR}$ E every 13 days); PUFA group: $\left(n=4 ; 4\right.$ kg/day Megalac ${ }^{\circledR} E 1$ ); Group PUFA+Vitamin E ( $n=4$; combination of groups PUFA and Vitamin $E$ treatments). Semen was collected from these animals on the day of insertion of the thermal bag, on the day of withdrawal, 30 and 60 days after. The results indicated that vitamin $E$ was effective for the improvement in damages caused by heat stress in sperm DNA and mitochondria, but only in samples collected from epididymis. Similarly, the combination of vitamin E and PUFA supplementation was effective in improving sperm motility patterns. The results of this study indicate that the combination of an antioxidant treatment with vitamin E and PUFA supplementation may be an interesting alternative to avoid the damage caused by acute heat stress in European bulls. However, possibly, this treatment would be more effective if performed preventively.

Keywords: Semen. Bos Taurus taurus. Oxidative stress. Vitamin E. Polyunsaturated fatty acids. 


\section{Lista de Tabelas}

Tabela 1- Efeitos das diferentes espécies reativas de oxigênio e do produto da peroxidação lipídica (Ânion: ânion superóxido; $\mathrm{H}_{2} \mathrm{O}_{2}$ : peróxido de hidrogênio; Hidroxil: radical hidroxila; MDA: malondialdeído) nas variaveis seminais de touros Bos taurus taurus 60 dias após a insulação - São Carlos, SP, 2011

Tabela 2 - Efeitos do tratamento da suplementacao de PUFA e Vitamina $E$ nas variaveis de semen fresco, de Bos taurus taurus, no tempo 0 (Controle). Sao Carlos-SP

Tabela 3 - Efeitos do tratamento da suplementacao de PUFA e Vitamina $E$ nas variaveis de semen fresco, de Bos taurus taurus, no tempo 1 (avaliacao após insulação testicular). Sao Carlos-SP.

Tabela 4 - Efeitos do tratamento da suplementacao de PUFA e Vitamina $E$ nas variaveis de semen fresco, de Bos taurus taurus, no tempo 30 (avaliacao após 30 dias de tratamento com suplementacao de PUFA e Vitamina E). Sao Carlos-SP.

Tabela 5 - Efeitos do tratamento da suplementacao de PUFA e Vitamina $E$ nas variaveis de semen fresco, de Bos taurus taurus, no tempo 60 (avaliacao após 60 dias de tratamento com suplementacao de PUFA e Vitamina E). Sao Carlos-SP.....

Tabela 6 - Efeitos do tratamento da suplementacao de PUFA e Vitamina $E$ nas variaveis de sêmen fresco, de Bos taurus taurus coletado da cauda do epidídimo imediatamente após castração realizada 75 dias após a insulação e início do tratamento com PUFAs e Vitamina E. Sao Carlos-SP, 2011.

Tabela 7 - Efeitos do tratamento da suplementacao de PUFA e Vitamina $E$ nas variaveis de semen criopreservado de Bos taurus taurus coletado da cauda do epidídimo imediatamente após castração realizada 75 dias após a insulação e início do tratamento com PUFAs e Vitamina E. Sao Carlos-SP, 2011. 


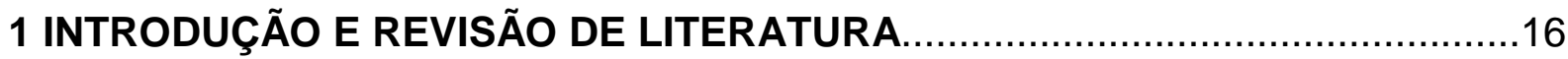

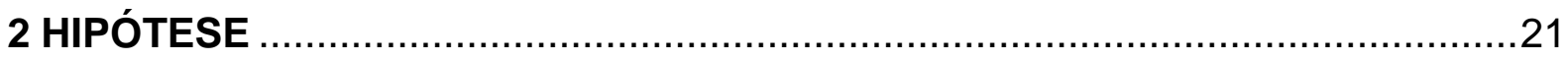

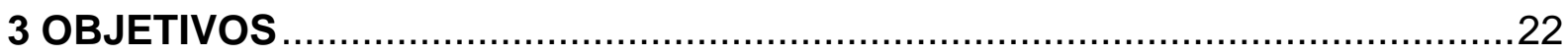

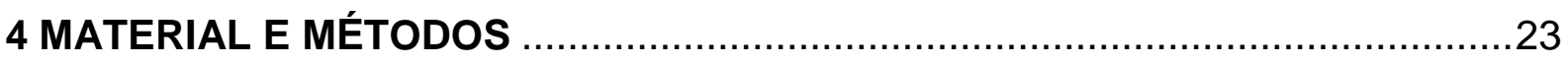

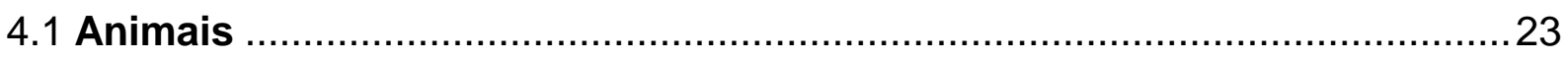

4.2 Dieta

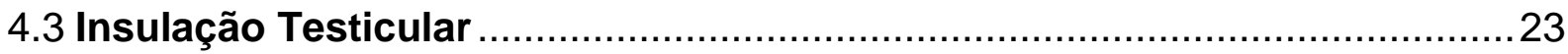

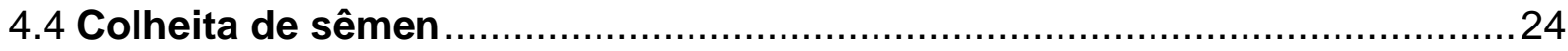

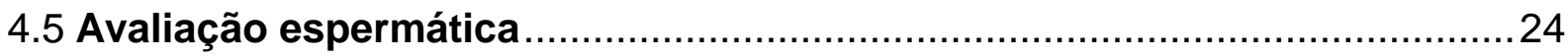

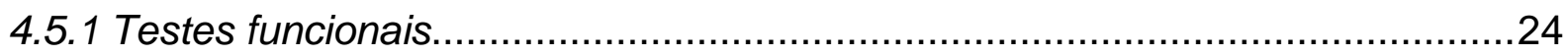

4.5.2 Avaliação da resistência ao estresse oxidativo ...........................................26

4.6 Experimento 1: Efeitos das diferentes espécies reativas de oxigênio e do produto da peroxidação lipídica, nas variáveis seminais de Bos taurus taurus submetidos ao estresse térmico testicular

4.7 Experimento 2: Efeito da suplementação dos ácidos graxos poliinsaturados (PUFA) e tratamento injetável com Vitamina E na qualidade seminal de touros Bos taurus submetidos ao estresse térmico testicular.

4.8 Experimento 3: Efeito da suplementação dos ácidos graxos poliinsaturados (PUFA) e tratamento injetável com Vitamina $E$ na qualidade dos espermatozoides colhidos da cauda do epidídimo de touros Bos taurus submetidos ao estresse térmico testicular.

4.8.1 Coleta de amostras espermáticas de epidídimo..........................................30

4.8.2 Criopreservação das amostras espermáticas de epidídimo .............................31

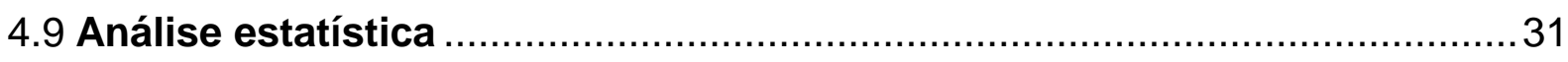

5 RESULTADOS E DISCUSSÃO .......................................................................33

5.1 Efeitos das diferentes espécies reativas de oxigênio e do produto da peroxidação lipídica, nas variáveis seminais de Bos taurus taurus submetidos ao estresse térmico testicular...

5.2 Efeito da suplementação dos ácidos graxos poliinsaturados (PUFA) e tratamento injetável com Vitamina E na qualidade seminal de touros Bos taurus submetidos ao estresse térmico testicular.

5.3 Efeito da suplementação dos ácidos graxos poliinsaturados (PUFA) e tratamento injetável com Vitamina E na qualidade dos espermatozoides colhidos da cauda do epidídimo de touros Bos taurus submetidos ao estresse térmico testicular 
6 CONCLUSÃO

45

REFERÊNCIAS 


\section{INTRODUÇÃO E REVISÃO DE LITERATURA}

Diversos estudos sugerem uma maior susceptibilidade ao estresse térmico em touros europeus quando comparados aos animais de origem zebuína (KUMIDIAKA; NAGARATNAM; RWUAAN, 1981; CHACON et al., 1999; NICHI, 2003; $\mathrm{NICHI}$ et al., 2006). Tal fato pode levar a perdas consideráveis na produtividade de um rebanho visto que, em regiões tropicais, a estação de monta ocorre no verão.

Segundo Nichi et al. (2006), uma explicação para a menor fertilidade dos touros europeus em relação aos zebuínos submetidos à condições tropicais, seria um maior índice de estresse oxidativo testicular. O estresse oxidativo é definido como um acúmulo de espécies reativas de oxigênio (reactive oxygen species - ROS) que causam danos à estrutura das biomoléculas, DNA, lipídios, carboidratos e proteínas, além de outros componentes celulares (SHARMA; AGARWAL, 1996). Em humanos, o estresse oxidativo foi identificado como causa de infertilidade em várias pesquisas. Para evitar $O$ ataque destas ROS, foram identificadas em sêmen humano, enzimas antioxidantes (superóxido dismutase - SOD; catalase e glutationa peroxidase-GPx), bem como outras substâncias com atividades semelhantes tais como a albumina, a glutationa, o piruvato, a taurina e hipotaurina e as vitaminas $\mathrm{E} e$ C (DE LAMIRANDE et al., 1997). No entanto, os espermatozoides são células extremamente sensíveis ao ataque das ROS por possuírem um reduzido citoplasma e uma alta quantidade de ácidos graxos poli-insaturados em sua membrana. $\mathrm{O}$ citoplasma reduzido limita a quantidade de antioxidantes enzimáticos, primordialmente intracitoplasmáticos (AITKEN, 1994). Por outro lado, a alta quantidade de ácidos graxos poli-insaturados, responsáveis pela maior fluidez de membrana, são mais facilmente clivados (MAZIERE et al., 1999; ROCARODRIGUEZ et al., 2014). Os ácido graxos poli-insaturados são moléculas que apresentam mais de uma ligação entre os átomos de hidrogênio e carbono. Do ponto de vista eletroquímico, ligações múltiplas possuem menor força de ligação individual, portanto estão mais sujeitas à perdas de átomos (e elétrons), fato este que as confere maior instabilidade (ALEXANDER-NORTH et al., 1994).Tais detalhes tornam-se ainda mais importantes para amostras submetidas à criopreservação, na qual o plasma seminal é diluído em extensores, diminuindo a capacidade 
antioxidante seminal. De fato, o estresse oxidativo tem sido relacionado como uma das causas pelos efeitos deletérios da criopreservação na célula espermática (THOMSON et al., 2009; SARIOZKAN et al., 2009; OLSZEWSKA-SLONINA, 2013).

É impossível abordar o estresse oxidativo (EO), sem entender primeiramente, o que é um radical livre; qualquer molécula, ou átomo com um ou mais elétrons despareados (ou seja, com muita afinidade de ligação), é considerada um radical livre. O EO é o resultado de um desequilíbrio entre a concentração de antioxidantes (agentes redutores) e concentração radicais livres (agentes oxidantes); este desequilíbrio, muitas vezes, ocorre em virtude de exacerbação da produção de ROS (NICHI, 2003).

Entre as espécies reativas de oxigênio, as mais importantes são o radical hidroxila $\left(\mathrm{OH}^{-}\right)$, o ânion superóxido $\left(\mathrm{O}_{2}^{-}\right)$, o peróxido de hidrogênio $\left(\mathrm{H}_{2} \mathrm{O}_{2}\right)$, e o óxido nítrico $\left(\mathrm{NO}_{2}\right)$ (AGARWAL; IKEMOTO; LOUGHLIN, 1994). Dentre estas, o ânion superóxido e o peróxido de hidrogênio são as ROS formadas primariamente, sendo - $\mathrm{H}_{2} \mathrm{O}_{2}$ gerado através da dismutase (enzimática ou não enzimática) do ânion superóxido (HALLIWELL, 1991; VOEIKOV, 2006). A ROS mais reativa e prejudicial é o radical hidroxila $\left(\mathrm{OH}^{-}\right)$, que pode ser formado através do $\mathrm{H}_{2} \mathrm{O}_{2}$ e do ânion superóxido, e através da reação do ânion superóxido com o óxido nítrico, produzindo

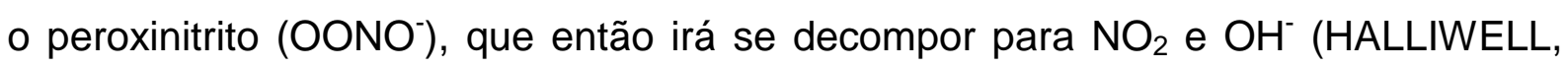
1991).

Embora, quando as ROS apresentam-se mais abundantes que os antioxidantes em um dado sistema acarretarem o EO, é importante frisar que estas moléculas instáveis, quando em concentração e momento adequado, participam também de processos fisiológicos tais como: hiperativação, capacitação e ligação do espermatozóide à zona pelúcida (NICHI, 2003).

Visto que um dos fatores envolvidos na maior susceptibilidade de touros europeus ao estresse térmico seria o estresse oxidativo, um possível tratamento visando evitar este efeito deletério seria a terapia antioxidante. O tratamento antioxidante para o tratamento da infertilidade tem sido estudado em diversas espécies, com resultados igualmente diversos, desde efeitos benéficos, ausência de efeitos e até mesmo efeitos deletérios (DONNELLY; MCCLURE; LEWIS, 1999; TUNC; THOMPSON; TREMELLEN, 2009; GHARAGOZLOO; AITKEN, 2011; MAYA- 
SORIANO et al., 2013; OLFATI KARAJI; DAGHIGH KIA; ASHRAFI, 2013 ${ }^{1}$; OURIQUE et al., 2013; YUN et al., 2013; DIAS et al., 2014²). Segundo Nichi et al. (2009), a eficiência de um tratamento depende de uma série de fatores, entre eles a presença de um estresse oxidativo suficiente para sobrepujar os mecanismos antioxidantes do meio, o local e o momento de ação do antioxidante deve ser o mesmo da ROS que esteja causando os danos, a concentração do antioxidante utilizado, e principalmente a qual ROS estaria levando a danos. Os antioxidantes, em geral, tem uma ação específica. Assim, o tratamento deve ser direcionado especificamente para a ROS mais prejudicial. Visto que as ROS apresentam papel fisiológico fundamental, um tratamento antioxidante inadequado poderia levar ao bloqueio de diversos mecanismos importantes para a célula espermática. Assim, a determinação de qual ROS é a mais deletéria a um determinado sistema poderia levar a um tratamento específico para a mesma podendo melhorar a eficiência do tratamento antioxidante para o animal ou mesmo para a amostra.

Por outro lado, apesar do efeito deletério, aumentando a susceptibilidade celular ao estresse oxidativo, o tratamento com ácidos graxos poli-insaturados (PUFA) na dieta pode ser uma outra alternativa para a melhora da qualidade espermática, principalmente em combinação com uma terapia antioxidante. Em animais, a suplementação com PUFA tem sido estudada em diversas espécies e diferentes processos fisiológicos, com resultados igualmente diversos tais como diminuição na pressão sanguínea em ratos hipertensivos (FRENOUX et al., 2001), diminuição da eclodibilidade de ovos em frangos (PAPPAS et al., 2005), ação benéfica porém moderada no tratamento da arterioesclerose em humanos (VON SCHACKY et al., 1999), inibição da carcinogênese mamária em ratos (MAILLARD et al., 2006). Em bovinos, particularmente, devido à degradação ruminal, a maioria dos ácidos graxos são degradados durante sua passagem pelo rúmen. No entanto, alguns trabalhos indicam que ácidos graxos n-3 de cadeia longa, podem escapar da degradação ruminal, levando a modificações na composição lipídica de carne e leite (ASHES et al., 1992).

\footnotetext{
${ }^{1}$ OLFATI KARAJI, R.; DAGHIGH KIA, H.; ASHRAFI, I. Effects of in combination antioxidant supplementation on microscopic and oxidative parameters of freeze-thaw bull sperm. Cell Tissue Banking, 2013. (No prelo)

${ }^{2}$ DIAS, T. R.; ALVES, M. G.; TOMAS, G. D.; SOCORRO, S.; SILVA, B. M.; OLIVEIRA, P. F. White Tea as a Promising Antioxidant Medium Additive for Sperm Storage at Room Temperature: A Comparative Study with Green Tea. J. Agric. Food. Chem., 2014. (No prelo)
} 
No espermatozoide, a função dos PUFA na constituição da membrana espermática e nos processos fisiológicos que levam à fertilização foi confirmada em diversos estudos em diferentes espécies (LANGLAIS; ROBERTS, 1985; LADHA, 1998). Além disto, estudos indicam que a composição lipídica da membrana espermática de diversas espécies também influencia a resistência ao choque frio (refrigeração e criopreservação) (PARKS; LYNCH, 1992). Em relação à célula espermática, a suplementação da dieta com PUFA em machos tem sido estudada em diversas espécies também com diferentes resultados, tanto negativos (AITKEN et al., 2006) como positivos (BRINSKO et al., 2005).

Visto ter sido comprovado que o estresse térmico de touros europeus poderia ser causado por uma aumento no estresse oxidativo, pode-se inferir que um tratamento que alterasse o perfil lipídico seminal ou espermático poderia causar enorme impacto para estes animais. Caso os PUFA sejam incorporados à membrana espermática, isto os tornaria ainda mais susceptíveis ao ataque das ROS, o que talvez pudesse ser evitado pelo tratamento com antioxidantes. Caso os PUFA apenas se incorporem ao plasma seminal, haveria uma maior quantidade de substrato para o ataque das ROS, o que pouparia as células espermáticas. Outro impacto dos PUFA em touros seria no caso de touros de centrais de inseminação. Neste caso, uma maior quantidade de PUFA na membrana espermática poderia levar a uma melhora na qualidade pós-descongelamento, levando a enormes ganhos na eficiência do processo.

A coleta de sêmen da cauda do epidídimo pode ser uma ferramenta bastante útil no caso da morte inesperada de animais de alto valor genético e de espécies em risco de extinção ou quando a coleta de sêmen por outras formas se torna inviável. A utilização de amostras espermáticas de epidídimo para sua utilização em biotécnicas reprodutivas tem sido estudada em diversas espécies tais como: cães (YU; LEIBO, 2002), servos (HISHINUMA; SUZUKI; SEKINE, 2003), porcos (IKEDA et al., 2002), carneiros (KAABI et al., 2003) e touros (FOOTE, 2000). A maioria dos experimentos objetivou avaliar a qualidade espermática e/ou a capacidade fertilizante. Outra justificativa para esta técnica seria o estudo das características espermáticas de um animal evitando o efeito do método de coleta e diminuindo-se os efeitos da coleta em si, independente de qual seja. 
Nichi et al. (2009) verificaram que amostras provenientes da cauda de epidídimo de touros Bos taurus taurus também são susceptíveis ao ataque das espécies reativas de oxigênio, sendo que a diminuição da qualidade destas amostras após a criopreservação pode estar relacionada a uma diminuição da capacidade antioxidante das células espermáticas. Estes autores verificaram uma diminuição considerável na resistência ao estresse oxidativo em amostras espermáticas coletadas de epidídimo submetidas à criopreservação. Houve também uma correlação negativa entre a fertilidade in vitro das amostras criopreservadas e as substâncias reativas ao ácido tiobarbitúrico (TBARS), um indicador da ocorrência da peroxidação lipídica.

Desta forma, sendo a menor fertilidade dos touros Bos taurus taurus em relação aos Bos taurus indicus submetidos ao estresse térmico explicada por uma maior produção de ROS não compensada por um aumento nos níveis de antioxidantes, um tratamento antioxidante seria uma ferramenta bastante interessante visando a melhora deste quadro. Em combinação com uma dieta rica em ácidos graxos poli-insaturados, este tratamento poderia até mesmo levar a um aumento na qualidade espermática pós-descongelação. No entanto, a determinação de qual espécie reativa mais deletéria poderia levar a um tratamento antioxidante direcionado. 


\section{HIPÓTESE}

Diferentes espécies reativas de oxigênio apresentam diferentes efeitos sobre espermatozoides provenientes de ejaculados e epidídimos de touros europeus

submetidos ao estresse térmico (insulação testicular) tratados ou não com antioxidantes 


\section{OBJETIVOS}

Os objetivos do presente experimento são:

- Estudar os efeitos da exposição ao ânion superóxido, o peróxido de hidrogênio, o radical hidroxila e a malondialdeído de amostras de ejaculados e sêmen epididimário provenientes de touros europeus submetidos à insulação testicular sobre a viabilidade espermática e peroxidação lipídica, visando a determinação de uma terapia antioxidante ideal para a melhora deste quadro;

- Realizar a combinação entre o tratamento antioxidante ideal e a suplementação com ácidos graxos poli-insaturados em touros europeus submetidos à insulação escrotal. 


\section{MATERIAL E MÉTODOS}

O presente estudo foi dividido em 3 experimentos. Inicialmente, nesta seção, serão descritos os procedimentos comuns a todos e, posteriormente, aqueles específicos de cada um deles.

Todos os reagentes utilizados foram obtidos da Sigma Chemical ${ }^{\circledR}$ ( St. Louis, MO, USA) sendo que as exceções serão informadas sempre que necessário.

Todos os procedimentos foram realizados de acordo com os princípios éticos de experimentação animal, sendo aprovado pela "Comissão de Ética no uso de animais" da Faculdade de Medicina Veterinária e Zootecnia da Universidade de São Paulo (número de protocolo 1681/2009).

\subsection{Animais}

Foram utilizados 16 touros de origem europeia (Bos taurus). Os touros possuíam idade compreendida entre 24 e 48 meses.

\subsection{Dieta}

Os animais recebiam cana de açúcar acrescida de resíduo úmido de cervejaria (cevada), sal mineral e ureia pecuária em cochos do tipo trenó. A água era fornecida em cochos ad libitum.

\subsection{Insulação Testicular}

A insulação testicular foi realizada por cinco (5) dias visando a degeneração testicular. A eficiência do processo foi aferida por medição da temperatura no interior 
das bolsas, ultrassonografia do parênquima testicular e colheita e avaliação seminal após retirada das bolsas

\subsection{Colheita de sêmen}

As colheitas foram realizadas com intervalos de 30 dias entre elas. O sêmen foi colhido através de eletroejaculação em tubo graduado, isolado de choque térmico e da luz (FLOYD et al., 1994).

\subsection{Avaliação espermática}

A avaliação imediata foi realizada por análise espermática computadorizada (CASA, Hamilton Thorn ${ }^{\circledR}$ ) para estudar possíveis diferenças entre as amostras referente à parâmetros de movimento espermático perceptíveis somente com a tecnologia supra-citada. Logo após colheita, uma aliquota foi fixada em solução de formol salina tamponada e destinada a análises de morfologia posteriores.

\subsubsection{Testes funcionais}

Os testes funcionais utilizados neste experimento foram a avaliação da integridade das membranas acrossomal e plasmática, avaliação da atividade citoquímica mitocondrial e avaliação da integridade da cromatina espermática.

Visando monitorar os possíveis danos causados durante a congelação das amostras, a técnica da Coloração Simples de Pope (POPE; ZHANG; DRESSER, 1991) foi utilizada para a avaliação da integridade estrutural da membrana acrossomal. Para tanto, uma alíquota de cada amostra $(5 \mu l)$ foi adicionada ao Corante Simples de Pope $(5 \mu \mathrm{l})$, sendo a mistura incubada por 70 segundos. Após incubação, foram feitos esfregaços sobre lâminas de microscopia, os quais foram 
analisados em microscópio convencional sob aumento de 1000 vezes. Foram contadas 200 células por lâmina, classificadas como:

Acrossomo Íntegro: região acrossomal de coloração lilás, levemente mais escura que a região pós-acrossomal;

Acrossomo Não-íntegro: região acrossomal de coloração rosa, levemente mais clara que a região pós-acrossomal

Para a avaliação da integridade da membrana plasmática, foi utilizada a coloração de Eosina-Nigrosina (E/N) segundo Barth e Oko (1989). Nesta coloração, por alterações na permeabilidade das membranas dos espermatozóides, a eosina cora estas células de rosa. Os espermatozóides com membranas íntegras não permitem a entrada do corante, portanto, contrastando com o plano de fundo tomado pela coloração escura da nigrosina, as células aparecem brancas. Desta maneira, uma alíquota de sêmen $(5 \mu l)$ foi misturado ao corante na proporção de 1:1 e realizados esfregaços sobre lâminas de microscopia. As lâminas foram analisadas em microscópio convencional sob aumento de 1000 vezes. Foram contadas 200 células por lâmina, classificadas como células com membrana íntegra (não coradas) e não-íntegra (coradas).

Segundo Hrudka (1987), a enzima Citocromo C-Oxidase (CCO) tem um papel fundamental no processo de respiração celular e metabolismo energético das células, além de ser pré-requisito para manutenção das funções osmótica e sintética, motilidade e integridade da estrutura celular. A técnica citoquímica desenvolvida por este autor baseia-se na oxidação da 3,3'-diaminobenzidina (DAB) pelo Complexo Citocromo C, o que inclui a CCO. Através de uma reação em cadeia, o DAB é polimerizado e se deposita nos locais onde ocorre a reação, ou seja, nas mitocôndrias. Esta deposição pode ser identificada através de microscopia convencional pela sua coloração marrom. Desta maneira, é possível descrever o declínio espontâneo da CCO ocasionado por tratamentos físicos e/ou químicos a que os espermatozóides são submetidos.

Para realização desta técnica, uma alíquota de $25 \mu \mathrm{l}$ de amostra foi incubada com $25 \mu \mathrm{L}$ de DAB (1mg/ml de PBS), a $37^{\circ} \mathrm{C}$, por uma hora. Após incubação, foram feitos esfregaços em lâmina de vidro e estas fixadas em formol a 10 por 10 minutos. As lâminas foram então lavadas e secas no ar sob proteção da luz.

A atividade citoquímica da mitocôndria espermática foi avaliada segundo descrito por Hrudka (1987). Desta maneira, as lâminas foram observadas em microscópio de 
contraste de fase, sob aumento de 1000 vezes, em imersão. Foram contados 200 espermatozóides/lâmina e classificados de acordo com a quantidade de corante visualizada na peça intermediária em 4 classes:

1 Classe I: células espermáticas com peça intermediária totalmente corada, alta atividade mitocondrial (DAB I);

2 Classe II: células espermáticas com segmentos corados (ativos) e não-corados (inativos), havendo predominância dos ativos (DAB II);

3 Classe III: células espermáticas com segmentos corados (ativos) e não-corados (inativos), havendo predominância dos inativos (DAB III);

4 Classe IV: células espermáticas com peça intermediária totalmente descorada, sem atividade mitocondrial (DAB IV).

Para o Teste de SCSA, foi utilizada metodologia proposta por Evenson et al. (1999). Para isso, uma palheta de sêmen de cada tratamento foi avaliada por citometria de fluxo. Resumidamente, o sêmen foi descongelado em banho-maria (37ํㅡ/30 segundos) e diluído em tampão TNE na concentração de $2 \times 106$ células $/ \mathrm{ml}$. Um volume de $0,1 \mathrm{ml}$ da diluição foi incubado com 0,2 $\mathrm{ml}$ de solução detergente (1\% de Triton $\mathrm{X}-100)$ por 30 segundos para permitir o acesso da LA ao DNA espermático. Após este período o sêmen foi incubado com $0,6 \mathrm{ml}$ de solução de LA $(6 \mu \mathrm{g} / \mathrm{ml})$. As amostras foram analisadas utilizando o citômetro de fluxo Guava EasyCyte, com excitação de 488 nm e 15 mW.

A avaliação da LA foi feita baseada na diferença entre a fluorescência emitida pelos espermatozóides com DNA íntegro (dupla fita), que emitem fluorescência verde e os com DNA fragmentado (fita simples), que emitem fluorescência vermelha.

\subsubsection{Avaliação da resistência ao estresse oxidativo}

A avaliação foi realizada com base na metodologia proposta por Ohkawa et al. (1979), que tem como fundamento a reação de duas moléculas de ácido tiobarbitúrico com uma molécula de malondialdeído (MDA), subproduto da peroxidação de lipídeos. Para isto foram utilizadas duas técnicas. O MDA 
espontâneo avaliado no plasma seminal (com valores em $\mathrm{mL}$ ) e o MDA dosado após o desafio com um agente indutor de estresse oxidativo (dosado em $10^{6}$ espermatozoides) .Para este último, foi empregado um sistema gerador de ROS com posterior mensuração da concentração de espécies reativas ao ácido tiobarbitúrico (TBARS) através da espectrofotometria, mensurando-se, portanto, a susceptibilidade das células à peroxidação lipídica.

Após o período de incubação, foram adicionados $1200 \mu \mathrm{L}$ de solução de ácido tricloroacético a $10 \%$ (TCA) e centrifugadas por 15 minutos, a $15^{\circ} \mathrm{C}$ e $5.000 \mathrm{~g}$, com a finalidade de separação de proteínas precipitadas. O mesmo foi realizado procedimento foi realizado com o plasma seminal utilizando $200 \mu \mathrm{L}$ de plasma seminal acrescido de $400 \mu \mathrm{L}$ de ácido tricloroacético.

Alíquotas de $1000 \mu \mathrm{L}$ de sobrenadante foram colocadas em tubos de ensaio juntamente com $1000 \mu \mathrm{L}$ de ácido tiobarbitúrico a 1\% (TBA). Os tubos contendo esta mistura foram incubados em banho-maria $\left(100^{\circ} \mathrm{C}\right)$ por 15 minutos e resfriados imediatamente em banho de gelo, com a finalidade de interrupção da reação termodependente.

A concentração de TBARS foi quantificada através de leitura em espectrofotômetro, num comprimento de onda de $532 \mathrm{~nm}$. Os resultados foram comparados com uma curva padrão, feita previamente, com malondialdeído.

A MDA é uma das principais substâncias que reagem com o ácido tiobarbitúrico e a concentração de TBARS é determinada utilizando-se o valor 1,56 $\mathrm{x}$ $105 \times \mathrm{M}^{-1} \mathrm{~mL}^{-1}$ como coeficiente de extinção molar do malondialdeído. A concentração de TBARS induzido nas amostras foi expressa em nanogramas de TBARS por $1 \times 10^{6}$ espermatozódes ( $\mathrm{ng} / 10^{6} \mathrm{sptz}$ ) e a concentração de TBARS espontâneo foi expressa em ng de TBARS por $\mathrm{mL}$ de plasma seminal.

\subsection{Experimento 1: Efeitos das diferentes espécies reativas de oxigênio e do produto da peroxidação lipídica, nas variáveis seminais de Bos taurus taurus submetidos ao estresse térmico testicular}

Sessenta dias após a insulação, o sêmen ejaculado de 4 animais foi dividido em 4 alíquotas de $100 \mu \mathrm{L}$ que foram submetidas a incubação com 4 sistemas 
distintos de produção de ROS (xantina + xantina oxidase que produzirá ânion superóxido; peróxido de hidrogênio; ferro + vitamina $C$ que produzirá radical hidroxila; malondialdeído: produto da peroxidação lipídica), como descrito abaixo:

1) Para produção do ânion superóxido foram utilizados $15 \mu \mathrm{L}$ de xantina $(0,0019 \mathrm{~g}$ em $25 \mathrm{~mL} \mathrm{NaOH} 0,0001 \mathrm{M})+5 \mu \mathrm{L}$ de xantina oxidase $(2 \mu \mathrm{L}$ em $200 \mu \mathrm{L}$ de EDTA $0,1 \mathrm{mM})+180 \mu \mathrm{L}$ de PBS em $400 \mu \mathrm{L}$ das amostras;

2) Para o peróxido de hidrogênio foram utilizados $41,21 \mu \mathrm{L}$ em $100 \mathrm{~mL}$ qsp PBS;

3) Para verificar a susceptibilidade ao malondialdeído, que é produto da peroxidação lipídica, foram utilizados $100 \mu \mathrm{L}$ de solução $(99,8346 \mu \mathrm{L}$ MDA + $10 \mathrm{~mL}$ água miliiq $+100 \mu \mathrm{L}_{2} \mathrm{SO}_{4}$ em $100 \mathrm{~mL}$ qsp PBS $)+100 \mu \mathrm{L}$ PBS em $400 \mu \mathrm{L}$ das amostras;

4) Para produção do radical hidroxil foram utilizados $100 \mu \mathrm{L}$ da solução de vitamina C $(20 \mathrm{mM}$ em $50 \mathrm{~mL}$ de solução fisiológica $0,9 \%)+100 \mu \mathrm{L}$ da solução de ferro (4mM em $50 \mathrm{~mL}$ de solução fisiológica $0,9 \%$ ) em $400 \mu \mathrm{L}$ das amostras.

Após as incubações as amostras foram então submetidas à avaliação espermática como descrito anteriormente.

\subsection{Experimento 2: Efeito da suplementação dos ácidos graxos poliinsaturados (PUFA) e tratamento injetável com Vitamina E na qualidade seminal de touros Bos taurus submetidos ao estresse térmico testicular}

De acordo com os resultados no experimento 1 , foi definido o tratamento antioxidante com Vitamina E (principal inibidor da peroxidação lipídica) para a combinação com a suplementação com ácidos graxos poli-insaturados. Os animais, foram submetidos à insulação escrotal e divididos em 4 grupos como descrito abaixo: 
Grupo Controle: $(n=4)$ Controle, recebeu $5 \mathrm{ml}$ de óleo mineral (placebo), via subcutânea, nos mesmo dias em que os outros grupos receberam vitamina $\mathrm{E}$.

Grupo Vitamina E: $(n=4) 5 \mathrm{ml}$ de Vitamina $E$ (Monovin® $E^{2}$ ) administrada via subcutânea a cada 13 dias após a retirada da bolsa durante 62 dias;

Grupo PUFA: ( $n=4)$ PUFA (Megalac ${ }^{8} E^{1}$ ) fornecido $4 \mathrm{Kg}$ ao dia por 62 dias, divididos em duas vezes ao dia, a partir da retirada da bolsa térmica;

Grupo PUFA+Vitamina E: ( $n=4)$ PUFA (Megalac ${ }^{\circledR} E^{3}$ ) fornecido $4 \mathrm{Kg}$ ao dia por 62 dias, divididos em duas vezes ao dia a partir da retirada da bolsa térmica $(17 / 07 / 2011)+5 \mathrm{ml}$ de Vitamina $E$ (Monovin ${ }^{8} E^{4}$ ), administrada por via subcutânea a cada 13 dias, após a retirada da bolsa, durante 62 dias (15/09/2011);

O sêmen ejaculado foi colhido a cada 30 dias (3 coletas; tempos 1, 30 e 60) e avaliado como descrito previamente.

\subsection{Experimento 3: Efeito da suplementação dos ácidos graxos poliinsaturados (PUFA) e tratamento injetável com Vitamina $E$ na qualidade dos espermatozoides colhidos da cauda do epidídimo de touros Bos taurus submetidos ao estresse térmico testicular}

Setenta e cinco dias após a insulação, todos os animais foram orquiectomizados sendo os testículos separados para a coleta de espermatozoides epididimários. Para a orquiectomia, os animais foram submetidos ao jejum hídrico e alimentar por 12 horas antes da cirurgia. Sedação e analgesia foram realizadas através de cloridrato de xilazina $1 \%$, na dosagem de $0,2 \mathrm{mg} / \mathrm{kg}$ de xilazina IM. e a

\footnotetext{
${ }^{3}$ Megalac ${ }^{\circledR}$ E - QGN- Arm \& Hammer ${ }^{\circledR}$

${ }^{4}$ Monovin $\AA$ E - Bravet ${ }^{\circledR}$
} 
área incisada foi anestesiada com cloridrato de lidocaína na dosagem de $10 \mathrm{~mL}$ de lidocaína 2\% intratesticular (pele, túnicas e funículos espermáticos).

A orquiectomia propriamente dita foi realizada através de incisões laterais (IL) de aproximadamente oito centímetros na pele do escroto e túnica vaginal, no sentido do ápice da bolsa escrotal. De modo a permitir boa visualização e exposição do testículo e do ligamento ínguino-testicular. A porção superior da túnica vaginal foi separada, o mesórquio restante foi isolado até atingir o máximo de adelgamento do cordão espermático que foi ligado com fio de sutura estéril (cat gut cromado 2). Cerca de três centímetros abaixo da ligadura, o cordão espermático foi emasculado para liberação total do testículo. O procedimento foi repetido para o testículo contralateral. A região incisada foi curada com cicatrizante (Sulfadiazina de prata) e repelente (Fipronil) tópicos. Durante o pós-operatório, os animais receberam antibióticoterapia com Cloridrato de Oxitetraciclina $10 \%$ longa ação $1 \mathrm{~mL} / \mathrm{Kg}$ peso vivo, IM, SID, dose única. A analgesia foi realizada por inibidor seletivo das cicloxigenases 1 e 2 (Flunixin Meglumine $1 \mathrm{~mL} / 45 \mathrm{Kg}$ de peso vivo), IM, BID, durante 3 dias.

\subsubsection{Coleta de amostras espermáticas de epidídimo}

Após a orquiectomia dos touros, os testículos foram dissecados. Amostras espermáticas de epidídimo foram colhidas através de pequenas incisões $(<1 \mathrm{~mm})$ na cauda do epidídimo utilizando-se um bisturi, sendo a amostra coletada através de uma pipeta automática. Tal procedimento era realizado após a pressionar-se a base da cauda do epidídimo com uma pinça homostática, o que aumentava a pressão interna permitindo que a amostra epididimária fluisse mais facilmente pela incisão. A fim de se evitar contaminação com sangue, as incisões foram realizadas com cuidado, na tentativa de se evitar a dissecção desnecessária de vasos ou tecidos. As amostras espermáticas coletadas foram diluídas em solução fisiológica $(\mathrm{NaCl}$ $0,9 \%$, submetidos a análise espermática previamente descrita. 


\subsubsection{Criopreservação das amostras espermáticas de epidídimo}

Após a colheita e avaliação imediata, as amostras epididimárias foram diluídas em meio Tris/glicerol até a concentração final de $10 \times 10^{6}$ espermatozoides por palheta $\left(20 \times 10^{6} \mathrm{sptz} / \mathrm{ml}\right)$.

As amostras diluídas foram envasado em palhetas de $0,5 \mathrm{ml}$, temperatura ambiente e acondicionadas em bolsas plásticas, insufladas em ar e vedadas, colocadas em refrigerador, em temperatura de $5^{\circ} \mathrm{C}$.

Após uma hora de refrigeração as palhetas foram acondicionadas horizontalmente, em estrutura de aço, onde só as extremidades estavam em contato com o metal. A estrutura de aço estava localizada à $3,5 \mathrm{~cm}$ de distância do nitrogênio líquido, contido em caixa de isopor

Decorridos 20 minutos em vapor de nitrogênio, as palhetas foram submersas no nitrogênio líquido, em seguida colocadas em raques e transferidas rapidamente para as canecas do botijão de criopreservação até a análise.

Após a descongelação (20 segundos a $37^{\circ} \mathrm{C}$ ), as amostras foram avaliadas como descrito anteriormente.

\subsection{Análise estatística}

Os dados foram analisados através do programa SAS System for Windows (2000).

Através do aplicativo Guided Data Analisys, os dados foram testados quanto à normalidade dos resíduos e homogeneidade das variâncias. Caso não obedecessem a estas premissas foram transformados (logarítmo na base $10-\log _{10}$ X; Raiz quadrada - RQ X; Quadrado $-\mathrm{X}^{2}$ ) e se a normalidade não fosse obtida empregava-se então, o procedimento NPAR1WAY de análise de variância não paramétrica. Diferenças significantes para os dados paramétricos foram avaliadas através do teste Least Square Differences (LSD). 
Para descrição dos resultados, foram empregados os erros padrões das médias e as médias (média \pm erro padrão da média) dos dados originais; e os níveis de significância $(p)$ dos dados originais, quando obedecessem às premissas: dos dados transformados, quando necessária a transformação; e dos dados analisados através da análise não paramétrica, quando não obedecessem às premissas e não houvessem transformações possíveis.

O nível de significância utilizado para rejeitar H0 (hipótese de nulidade) foi de $5 \%$, isto é, para um nível de significância menor que 0,05, considerou-se que ocorreram diferenças estatísticas entre as variáveis classificatórias (concentrações de GSH) para uma determinada variável resposta. 


\section{RESULTADOS E DISCUSSÃO}

Os resultados apresentados abaixo foram divididos em três partes, de acordo com os três experimentos realizados. A primeira parte consiste na avaliação do efeito das diferentes espécies reativas de oxigênio e do subproduto da peroxidação lipídica (malondialdeído) nas variáveis seminais de touros Bos taurus submetidos ao estresse térmico testicular. A segunda parte corresponde à avaliação do efeito da suplementação dos ácidos graxos poliinsaturados (PUFA) e tratamento injetável com Vitamina $E$ na qualidade seminal destes animais. Por outro lado, a terceira parte compreende na avaliação do efeito destes tratamentos nos espermatozoides "in natura" e criopreservados coletados da cauda do epidídimo pós-orquiectomia bilateral.

\subsection{Efeitos das diferentes espécies reativas de oxigênio e do produto da peroxidação lipídica, nas variáveis seminais de Bos taurus taurus submetidos ao estresse térmico testicular}

Abaixo estão descritos os resultados referentes aos efeitos das diferentes espécies reativas de oxigênio (Ânion: ânion superóxido; $\mathrm{H}_{2} \mathrm{O}_{2}$ : peróxido de hidrogênio; Hidroxil: radical hidroxil) e produto da peroxidação lipídica (malondialdeído) nas variáveis seminais de Bos taurus taurus (sêmen fresco) submetidos ao estresse térmico testicular (Tabela 1)

Para avaliar esses resultados levamos em consideração que o tempo 60 após a insulação para a avaliação do efeito das induções com diferentes espécies reativas de oxigênio e do subproduto da peroxidação lipídica nas amostras seminais. Dessa forma, os resultados encontrados nas tabelas acima correspondem também as injúrias provocadas pela insulação testicular, que já estão comprovadas através de trabalhos publicados anteriormente, com o desafio da indução das espécies acimas citadas (AUSTIN; MURPHREE; HUPP, 1961; NEWTON et al., 2009; FRIJTERS et al., 2011). Podemos observar nesses resultados que o Malondialdeído 
(MDA) foi que causou mais efeito deletério na grande maioria das variáveis que apresentaram diferença estatística. O Ânion Superóxido, por outro lado, foi o menos lesivo (Tabela 1). O desafio oferecido pelo aumento de temperatura induzido, desencadeou um desequilíbrio nas concentrações de SOD e GPX bem como produziu uma cascata de eventos deletérios aos espermatozóides. Os resultados obtidos nos animais logo após a insulação testicular indicaram que, em geral, os espermatozoides eram bastante susceptíveis ao Malondialdeído, importante produto do ataque das espécies reativas de oxigênio (ROS) aos lipídeos. Neste contexto, um tratamento antioxidante de eleição seria a Vitamina $\mathrm{E}$, antioxidante lipossolúvel conhecido por inibir a peroxidação lipídica de ácidos graxos poli-insaturados de membranas biológicas (BECONI et al., 1991; ERNSTER; FORSMARK; NORDENBRAND, 1992).

Tabela 1 - Efeitos das diferentes espécies reativas de oxigênio e do produto da peroxidação lipídica (Ânion: ânion superóxido; $\mathrm{H}_{2} \mathrm{O}_{2}$ : peróxido de hidrogênio; Hidroxil: radical hidroxila; MDA: malondialdeído) nas variaveis seminais de touros Bos taurus taurus 60 dias após a insulação - São Carlos, SP - 2011

\begin{tabular}{lrrrr} 
& Anion & \multicolumn{1}{c}{$\mathrm{H}_{2} \mathrm{O}_{2}$} & \multicolumn{1}{c}{ MDA } & \multicolumn{1}{c}{ Hidroxil } \\
\hline VIVO & $51,00 \pm 9,00^{\mathrm{b}}$ & $71,50 \pm 5,50^{\mathrm{ab}}$ & $4,00 \pm 2,00^{\mathrm{c}}$ & $73,50 \pm 2,50^{\mathrm{a}}$ \\
ACRO & $72,50 \pm 8,50$ & $69,50 \pm 17,50$ & $38,50 \pm 6,50$ & $68,50 \pm 21,50$ \\
DABI & $45,50 \pm 2,50^{\mathrm{a}}$ & $45,00 \pm 1,00^{\mathrm{a}}$ & $0,00 \pm 0,00^{\mathrm{b}}$ & $49,50 \pm 0,50^{\mathrm{a}}$ \\
DABII & $15,00 \pm 5,00^{\mathrm{ab}}$ & $21,00 \pm 9,00^{\mathrm{a}}$ & $0,50 \pm 0,50^{\mathrm{b}}$ & $11,00 \pm 1,00^{\mathrm{ab}}$ \\
DABIII & $1,50 \pm 1,50$ & $3,00 \pm 2,00$ & $1,00 \pm 1,00$ & $1,00 \pm 1,00$ \\
DABIV & $37,50 \pm 3,50^{\mathrm{b}}$ & $31,00 \pm 12,00^{\mathrm{b}}$ & $98,50 \pm 1,50^{\mathrm{a}}$ & $38,50 \pm 2,50^{\mathrm{b}}$ \\
MDA (mL) & $6263,0 \pm 3444,9^{\mathrm{b}}$ & $5410,1 \pm 2989,2^{\mathrm{b}}$ & $235440,5 \pm 30963^{\mathrm{a}}$ & $8730,1 \pm 4314,86^{\mathrm{b}}$ \\
MDA (x10 ${ }^{\mathrm{b}}$ Sptz) & $7,63 \pm 0,00^{\mathrm{b}}$ & $311,00 \pm 0,00^{\mathrm{b}}$ & $83002,99 \pm 0,00^{\mathrm{a}}$ & $113,09 \pm 102,73^{\mathrm{b}}$ \\
VAP & $71,40 \pm 71,40$ & $42,75 \pm 42,75$ & $31,55 \pm 31,55$ & $133,55 \pm 43,15$ \\
VSL & $3,25 \pm 3,25$ & $0,00 \pm 0,00$ & $0,00 \pm 0,00$ & $6,60 \pm 1,10$ \\
VCL & $18,60 \pm 18,60$ & $9,30 \pm 9,30$ & $25,00 \pm 25,00$ & $33,95 \pm 2,35$ \\
ALH & $42,50 \pm 42,50$ & $36,50 \pm 36,50$ & $35,50 \pm 35,50$ & $84,50 \pm 3,50$ \\
BCF & $24,50 \pm 24,50$ & $19,50 \pm 19,50$ & $19,50 \pm 19,50$ & $47,00 \pm 5,00$ \\
STR & $21,50 \pm 21,50$ & $22,50 \pm 22,50$ & $11,00 \pm 11,00$ & $40,00 \pm 1,00$ \\
LIN & $504,00 \pm 213,00^{\mathrm{ab}}$ & $291,00 \pm 11,00^{\mathrm{b}}$ & $333,00 \pm 114,00^{\mathrm{ab}}$ & $943,00 \pm 205,00^{\mathrm{a}}$ \\
ELONGATION & $0,00 \pm 0,00$ & $0,00 \pm 0,00$ & $0,00 \pm 0,00$ & $0,00 \pm 0,00$ \\
MOTILEPCT & $0,00 \pm 0,00$ & $0,00 \pm 0,00$ & $0,00 \pm 0,00$ & $0,00 \pm 0,00$ \\
PROGRESSIVE & $0,00 \pm 0,00$ & $0,00 \pm 0,00$ & $0,00 \pm 0,00$ & $0,00 \pm 0,00$ \\
RAPID & $0,00 \pm 0,00$ & $0,00 \pm 0,00$ & $0,00 \pm 0,00$ & $0,00 \pm 0,00$ \\
MEDIUM & $0,00 \pm 0,00$ & $0,00 \pm 0,00$ & $0,00 \pm 0,00$ & $0,00 \pm 0,00$ \\
SLOW & $0,00 \pm 0,00$ & $0,00 \pm 0,00$ & $0,00 \pm 0,00$ & $0,00 \pm 0,00$ \\
STATIC & $0,00 \pm 0,00$ & $0,00 \pm 0,00$ & $0,00 \pm 0,00$ & $0,00 \pm 0,00$ \\
\hline \hline
\end{tabular}

a,b,c: letras diferentes indicam diferença estatística $(p<0,05)$ 


\subsection{Efeito da suplementação dos ácidos graxos poliinsaturados (PUFA) e tratamento injetável com Vitamina E na qualidade seminal de touros Bos taurus submetidos ao estresse térmico testicular}

Abaixo estão descritos os resultados das avaliações seminais antes da insulação escrotal (tempo 0; Tabela 2), imediatamente após a retirada das bolsas de insulação (tempo 1; Tabela 3), 30 dias após o início dos tratamentos (tempo 30; Tabela 4) e 60 dias após o início dos tratamentos (tempo 60; Tabela 4).

Nos tempos 0 (controle; Tabela 2) e 1 (pós-insulação; Tabela 3), como era esperado, não foram observadas diferenças estatísticas nas variáveis avaliadas, pois não houve tempo suficiente para aferição de qualquer resultado estatístico significante, já que os tratamentos ainda não começaram nestes tempos .

Tabela 2 - Efeitos do tratamento da suplementacao de PUFA e Vitamina E nas variaveis de semen fresco, de Bos taurus taurus, no tempo 0 (Controle) - São Carlos-SP

\begin{tabular}{|c|c|c|c|c|}
\hline & Controle & Vitamina E & PUFA & PUFA+Vitamin E \\
\hline VIVO & $60,67 \pm 7,69$ & $64,00 \pm 8,96$ & $57,00 \pm 13,10$ & $43,50 \pm 8,86$ \\
\hline ACRO & $69,00 \pm 10,69$ & $65,00 \pm 13,58$ & $63,25 \pm 7,61$ & $52,00 \pm 13,74$ \\
\hline DABI & $62,00 \pm 5,86$ & $45,33 \pm 12,17$ & $43,00 \pm 19,01$ & $45,50 \pm 17,35$ \\
\hline DABII & $13,67 \pm 1,76^{\mathrm{ab}}$ & $20,67 \pm 2,33^{a}$ & $9,25 \pm 3,30^{\mathrm{b}}$ & $12,75 \pm 2,56^{\mathrm{ab}}$ \\
\hline DABIII & $5,00 \pm 1,53$ & $8,33 \pm 6,89$ & $6,25 \pm 2,78$ & $12,75 \pm 5,95$ \\
\hline DABIV & $19,33 \pm 4,91$ & $25,67 \pm 4,41$ & $41,50 \pm 17,08$ & $29,00 \pm 10,38$ \\
\hline MDA (mL) & $129,03 \pm 22,84$ & $125,78 \pm 56,23$ & $223,80 \pm 66,08$ & $135,65 \pm 26,28$ \\
\hline MDA (x106 sptz) & $924,85 \pm 907,05$ & $158,98 \pm 99,76$ & $657,00 \pm 578,78$ & $515,48 \pm 328,70$ \\
\hline SOD & $70,32 \pm 30,20$ & $54,17 \pm 16,00$ & $106,69 \pm 17,61$ & $130,34 \pm 52,54$ \\
\hline GPX & $608,36 \pm 183,32$ & $878,86 \pm 431,21$ & $686,66 \pm 177,24$ & $667,28 \pm 263,36$ \\
\hline DNA & $4,03 \pm 1,55$ & $4,37 \pm 0,98$ & $17,59 \pm 7,88$ & $20,26 \pm 11,40$ \\
\hline VAP & $108,47 \pm 10,73$ & $105,77 \pm 14,56$ & $83,30 \pm 2,58$ & $110,88 \pm 15,48$ \\
\hline VSL & $94,70 \pm 8,50$ & $91,97 \pm 12,84$ & $63,43 \pm 7,91$ & $97,23 \pm 12,79$ \\
\hline VCL & $162,17 \pm 7,90$ & $165,47 \pm 24,37$ & $113,30 \pm 26,32$ & $176,43 \pm 26,38$ \\
\hline ALH & $5,70 \pm 0,17$ & $5,73 \pm 0,76$ & $165,00 \pm 159,33$ & $6,65 \pm 0,55$ \\
\hline $\mathrm{BCF}$ & $40,30 \pm 0,70^{a b}$ & $43,20 \pm 0,7^{\mathrm{a}} 8$ & $36,64 \pm 1,73^{b}$ & $40,53 \pm 2,32^{a b}$ \\
\hline STR & $85,67 \pm 2,60$ & $87,33 \pm 0,88$ & $67,38 \pm 15,89$ & $85,75 \pm 2,66$ \\
\hline LIN & $60,33 \pm 2,33$ & $59,00 \pm 0,58$ & $65,00 \pm 12,99$ & $55,75 \pm 3,30$ \\
\hline ELONGATION & $49,33 \pm 3,33$ & $48,33 \pm 1,20$ & $35,25 \pm 10,42$ & $47,50 \pm 2,72$ \\
\hline MOTILE & $69,67 \pm 13,53$ & $75,33 \pm 9,74$ & $30,25 \pm 16,10$ & $42,00 \pm 20,64$ \\
\hline PROGRESSIVE & $51,33 \pm 12,25^{a b}$ & $57,33 \pm 6,94^{a}$ & $16,75 \pm 7,38^{b}$ & $31,00 \pm 15,69^{a b}$ \\
\hline RAPID & $61,00 \pm 15,72$ & $65,67 \pm 8,82$ & $22,50 \pm 11,89$ & $37,50 \pm 19,37$ \\
\hline MEDIUM & $8,67 \pm 2,19$ & $9,67 \pm 4,26$ & $166,50 \pm 157,21$ & $4,25 \pm 2,63$ \\
\hline SLOW & $15,33 \pm 2,73$ & $10,67 \pm 1,76$ & $21,56 \pm 6,80$ & $14,00 \pm 5,48$ \\
\hline STATIC & $15,33 \pm 12,84$ & $14,00 \pm 8,19$ & $42,00 \pm 26,27$ & $43,75 \pm 23,25$ \\
\hline
\end{tabular}

$a, b, c$ : letras diferentes indicam diferença estatística $(p<0,05)$ 
Tabela 3 - Efeitos do tratamento da suplementacao de PUFA e Vitamina E nas variaveis de semen fresco, de Bos taurus taurus, no tempo 1 (avaliacao após insulação testicular) - São Carlos-SP

\begin{tabular}{|c|c|c|c|c|}
\hline & Controle & Vitamina $\mathrm{E}$ & PUFA & PUFA+Vitamina E \\
\hline VIVO & $41,50 \pm 7,38$ & $50,67 \pm 7,84$ & $32,50 \pm 17,27$ & $45,33 \pm 5,04$ \\
\hline ACRO & $28,50 \pm 12,04$ & $58,33 \pm 9,39$ & $52,25 \pm 13,41$ & $38,00 \pm 12,12$ \\
\hline DABI & $44,25 \pm 14,46$ & $57,33 \pm 7,54$ & $43,75 \pm 16,05$ & $55,00 \pm 14,57$ \\
\hline DABII & $10,50 \pm 3,86$ & $19,67 \pm 2,40$ & $17,00 \pm 6,12$ & $14,00 \pm 3,06$ \\
\hline DABIII & $11,00 \pm 4,85$ & $6,00 \pm 2,52$ & $12,75 \pm 5,86$ & $7,00 \pm 2,31$ \\
\hline DABIV & $34,25 \pm 16,29$ & $17,00 \pm 9,61$ & $26,50 \pm 15,74$ & $24,00 \pm 15,00$ \\
\hline MDA (mL) & $166,99 \pm 77,46$ & $129,86 \pm 30,17$ & $103,72 \pm 55,46$ & $353,70 \pm 121,14$ \\
\hline MDA (x10 $\mathrm{sptz})$ & $74,58 \pm 39,35$ & $315,39 \pm 284,65$ & $192,84 \pm 121,04$ & $30,11 \pm 7,59$ \\
\hline SOD & $114,86 \pm 12,54$ & $55,01 \pm 21,51$ & $78,54 \pm 26,43$ & $93,21 \pm 37,17$ \\
\hline GPX & $292,60 \pm 105,94$ & $722,35 \pm 293,86$ & $526,69 \pm 231,89$ & $516,48 \pm 134,27$ \\
\hline DNA & $12,44 \pm 8,32$ & $16,26 \pm 10,88$ & $15,72 \pm 5,60$ & $12,91 \pm 3,74$ \\
\hline VAP & $117,03 \pm 4,86^{a}$ & $121,67 \pm 4,87^{\mathrm{a}}$ & $60,10 \pm 11,29^{b}$ & $109,90 \pm 10,56^{a b}$ \\
\hline VSL & $97,43 \pm 6,01^{a}$ & $105,03 \pm 2,64^{a}$ & $50,30 \pm 9,80^{b}$ & $96,00 \pm 8,73^{a}$ \\
\hline VCL & $201,73 \pm 1,01^{a}$ & $194,03 \pm 9,58^{a}$ & $109,18 \pm 20,54^{b}$ & $179,30 \pm 22,65^{a}$ \\
\hline $\mathrm{ALH}$ & $8,00 \pm 0,35^{a}$ & $6,77 \pm 0,15^{a}$ & $3,13 \pm 1,56^{b}$ & $6,37 \pm 0,88^{a b}$ \\
\hline $\mathrm{BCF}$ & $39,83 \pm 0,75$ & $41,07 \pm 0,88$ & $45,70 \pm 4,86$ & $41,20 \pm 1,15$ \\
\hline STR & $81,67 \pm 1,76$ & $86,00 \pm 2,00$ & $87,00 \pm 4,02$ & $86,00 \pm 0,00$ \\
\hline LIN & $49,67 \pm 3,18$ & $57,00 \pm 1,00$ & $53,00 \pm 4,49$ & $55,33 \pm 1,67$ \\
\hline ELONGATION & $45,00 \pm 0,58^{a}$ & $45,00 \pm 1,00^{a}$ & $34,25 \pm 4,52^{b}$ & $44,33 \pm 2,96^{a b}$ \\
\hline MOTILE & $54,67 \pm 12,99^{a b}$ & $68,33 \pm 10,4^{\mathrm{ab}} 0$ & $19,00 \pm 14,8^{a} 0$ & $58,67 \pm 15,51^{a b}$ \\
\hline PROGRESSIVE & $40,00 \pm 9,71^{a b}$ & $52,00 \pm 7,64^{a}$ & $10,00 \pm 7,84^{b}$ & $46,00 \pm 12,90^{a}$ \\
\hline RAPID & $49,33 \pm 12,20^{a b}$ & $60,67 \pm 6,49^{a}$ & $13,25 \pm 11,04^{b}$ & $52,33 \pm 15,21^{a}$ \\
\hline MEDIUM & $5,33 \pm 1,45$ & $8,00 \pm 4,04$ & $5,50 \pm 3,86$ & $6,33 \pm 1,86$ \\
\hline SLOW & $17,00 \pm 3,46^{a b}$ & $11,33 \pm 3,8^{b} 4$ & $11,50 \pm 4,21^{b}$ & $26,00 \pm 2,31^{a}$ \\
\hline STATIC & $28,00 \pm 9,81^{\mathrm{ab}}$ & $20,00 \pm 7,37^{b}$ & $69,00 \pm 19,09^{a}$ & $15,33 \pm 15,33^{b}$ \\
\hline
\end{tabular}

a,b,c: letras diferentes indicam diferença estatística $(p<0,05)$

Pudemos observar que com 30 dias de tratamento a Vitamina $E$ não foi capaz de driblar os efeitos do estresse oxidativo e a suplementação com PUFA apresentou um efeito de aumento na peroxidacão lipídica. Por outro lado, com o aumento da peroxidacao lipídica, houve um aumento nos níveis de SOD possivelmente visando amenizar esse processo. $O$ tratamento com PUFA nos tempo 30 e 60 melhorou a qualidade de movimento da célula espermática. O MDA espontâneo, nos grupos que receberam VIT E e PUFA apresentaram aumento significante de TBARS em relação ao controle (Tabela 4; MDA (mL); PUFA e Vitamina E:378,53 $\pm 68,63$ vs. Controle: $354,27 \pm 133,40$ ). As células espermáticas, em especial são altamente susceptíveis ao ataque de espécies reativas ao oxigênio (ROS), devido a presença de PUFAs, que possuem duplas ligações entre carbonos (LENZI et al., 1994). Desta forma a 
suplementacao de PUFAs, torna o espermatozóide mais susceptível ao ataque das ROS. Associado a este evento, observamos uma diminuição da SOD, nos grupos tratados com PUFAs, em relação ao controle (Tabela 4; SOD; PUFA e Vitamina $E: 110,75 \pm 14,48$, PUFA:64,28 $\pm 21,74$ vs. Controle: $151,13 \pm 18,52)$. De fato, com o aumento da peroxidacao lipidica, a SOD, sendo a primeira linha de defesa na cascata de eventos oxidativos, tentaria agir na tentativa de amenizar o estresse oxidativo, sendo mais consumida, pois na reação catalisada pelas SODs, duas moléculas de ânion superóxido $\left(\mathrm{O}_{2^{-}}\right)$formam uma molécula de $\mathrm{O}_{2}$ e uma de $\mathrm{H}_{2} \mathrm{O}_{2}$, esta última destruída posteriormente pela catalase ou pelo sistema glutationa peroxidase. Segundo Matés (2000). Em experimento realizado por Alvarez et al. (1987), altas correlações foram encontradas entre a atividade da superóxido dismutase com o índice de peroxidação lipídica espontânea $(r=-0,97, p<0,05)$ e com o tempo de perda de motilidade $(r=0,87, p<0,05)$, em amostras de sêmen humano, indicando ser a SOD, o principal mecanismo de proteção contra a peroxidação lipídica em humanos.

Em relação a vitamina $E$ não ter conseguido driblar tais efeitos, pode ser atribuído ao fato de que este antioxidante é um composto lipidico também sujeito a peroxidacao e seu efeito antioxidante e relacionado também a presença de Vitamina $C$ a qual a regenera, de modo que, muito provavelmente, houve incremento de Vitamina $\mathrm{E}$ oxidada e não reduzida. Portanto, o subproduto da peroxidacao lipídica mostrar-se-ia mais elevado como observado acima. Os grupos que receberam a suplementação. O $\alpha$-tocoferol atua na membrana plasmática, como um antioxidante lipo-solúvel, prevenindo a reação oxidativa em cadeia (MATÉS, 2000) . O ácido ascórbico atua na proteção do citocromo P-450 contra a destruição por pseudosubstratos oxidativos e oxigênio (FRAGA et al., 1991). Por outro lado, sabe-se que existe uma interação entre vitaminas $E$ e $C$. A vitamina $E$ e regenerada do radical tocoferil (radical formado após a destruição do radical hidroxila pela vitamina $E$ ) pela doação de um átomo de hidrogênio pela vitamina C (PACKER; SLATER; WILLSON, 1979; MUKAI; NISHIMURA; KIKUCHI, 1991). Assim, forma-se uma reação em cadeia em que mais vitamina $E$ formada.

Outra hipótese para explicar a parcial ineficiência da Vitamina E seria que as lesões causadas pelo estresse térmico agudo promovido pela insulação testicular não envolveriam apenas ao estresse oxidativo. De fato, segundo Paul, Teng e Saunders (2009), os danos causados pelo estresse térmico agudo podem ser 
induzidos por três fatores principais: a apoptose, o estresse oxidativo e a hipóxia. Sabe-se que para o melhor funcionamento do testículo é necessário que o mesmo permaneça entre 2 a $8^{\circ} \mathrm{C}$ abaixo da temperatura corporal (IVELL, 2007; KANTER; AKTAS; ERBOGA, 2013). Além disto, a vascularização testicular é bastante limitado, possivelmente visando limitar o metabolismo celular. Com um aumento de temperatura, e o consequente aumento no metabolismo, ocorre uma necessidade de maior vascularização, o que não é possível para a maior parte do tecido testicular. Desta forma, o testículo se torna hipóxico (REYES et al., 2012). A hipóxia, ocorre quando a tensão de oxigênio cai para níveis abaixo dos necessário para o funcionamento normal de um determinado tecido, o que pode levar ao bloqueio do desenvolvimento celular (IIDA et al., 2002), à apoptose (CARMELIET et al., 1998), a danos no DNA espermático (HOU et al., 2012), a problemas na expressão de proteínas (TAYLOR et al., 2010).

Verificamos que variáveis relacionadas ao movimento das células espermáticas, avaliadas pelo CASA apresentaram-se mais elevadas no grupo tratado com PUFA e Vitamina E (e.g., STR, BCF e PROGRESSIVE) (Tabelas 4 e 5). Estes resultados corroboram resultados anteriores comprovando que quanto maior a quantidade de PUFA melhor a motilidade, consequência da maior fluidez das membranas (ROBINSON et al., 2006). De fato, esperava-se que a interação entre a suplementação com PUFA e o tratamento com Vitamina $E$ levasse a um aumento nos padrões de motilidade espermática. Os ácidos graxos poli-insaturados por apresentaram uma configuração especial apresentando dobras nas ligações duplas, quando presentes na membrana, levam a uma desestabilização desta membrana (LENZI et al., 1994). Assim, com o aumento na quantidade de ácidos graxos poliinsaturados na membrana espermática, a membrana apresentaria uma maior fluidez, o que permitiria um aumento na motilidade espermática. 
Tabela 4 - Efeitos do tratamento da suplementação de PUFA e Vitamina E nas variáveis de sêmen fresco, de Bos taurus taurus, no tempo 30 (avaliação após 30 dias de tratamento com suplementação de PUFA e Vitamina E) - São Carlos-SP

\begin{tabular}{lcccc} 
& Controle & Vitamins $\mathrm{E}$ & PUFA & PUFA+Vitamina E \\
\cline { 2 - 5 } VIVO & $46,00 \pm 11,11$ & $47,00 \pm 22,14$ & $62,75 \pm 7,42$ & $56,75 \pm 15,40$ \\
ACRO & $69,75 \pm 6,36$ & $57,67 \pm 5,90$ & $66,75 \pm 12,41$ & $59,25 \pm 11,25$ \\
DABI & $42,50 \pm 16,00$ & $58,33 \pm 17,90$ & $34,50 \pm 2,63$ & $24,50 \pm 9,46$ \\
DABII & $5,25 \pm 2,06$ & $2,33 \pm 0,67$ & $4,50 \pm 1,55$ & $2,75 \pm 1,60$ \\
DABIII & $2,75 \pm 1,11$ & $3,33 \pm 1,20$ & $4,75 \pm 2,46$ & $1,50 \pm 1,19$ \\
DABIV & $49,50 \pm 16,66$ & $36,00 \pm 17,04$ & $56,25 \pm 3,97$ & $71,25 \pm 10,52$ \\
MDA (mL) & $354,27 \pm 133,40^{\mathrm{b}}$ & $732,00 \pm,^{\mathrm{a}}$ & $322,18 \pm 55,96^{\mathrm{b}}$ & $378,53 \pm 68,63^{\text {ab }}$ \\
MDA (x10 ${ }^{\mathrm{b}}$ sptz) & $1429,73 \pm 1348,43$ & $245,19 \pm 231,74$ & $433,41 \pm 307,71$ & $29,84 \pm 14,62$ \\
SOD & $151,13 \pm 18,52^{\mathrm{a}}$ & $98,22 \pm,^{\mathrm{ab}}$ & $64,28 \pm 21,74^{\mathrm{b}}$ & $110,75 \pm 14,48^{\text {ab }}$ \\
GPX & $953,81 \pm 719,23$ & $774,28 \pm$, & $343,17 \pm 160,48$ & $645,98 \pm 297,52$ \\
DNA & $13,31 \pm 3,09$ & $60,10 \pm$ & $35,53 \pm 18,18$ & $36,07 \pm 12,02$ \\
VAP & $67,58 \pm 14,66$ & $99,53 \pm 15,27$ & $89,65 \pm 12,61$ & $106,10 \pm 24,81$ \\
VSL & $56,68 \pm 14,01$ & $78,40 \pm 11,40$ & $80,83 \pm 13,17$ & $93,90 \pm 22,78$ \\
VCL & $114,48 \pm 16,34$ & $170,53 \pm 25,70$ & $135,73 \pm 11,27$ & $161,23 \pm 35,63$ \\
ALH & $5,73 \pm 0,57$ & $6,70 \pm 0,49$ & $5,23 \pm 0,53$ & $5,65 \pm 0,90$ \\
BCF & $37,78 \pm 2,55$ & $36,40 \pm 4,63$ & $37,58 \pm 1,83$ & $39,53 \pm 1,49$ \\
STR & $81,50 \pm 3,40^{\text {ab }}$ & $79,00 \pm 0,58^{\mathrm{b}}$ & $88,50 \pm 2,90^{\mathrm{a}}$ & $85,75 \pm 2,25^{\mathrm{ab}}$ \\
LIN & $51,75 \pm 3,57$ & $50,00 \pm 2,89$ & $61,50 \pm 4,84$ & $58,25 \pm 3,94$ \\
ELONGATION & $42,75 \pm 2,10$ & $45,67 \pm 1,45$ & $43,50 \pm 1,26$ & $47,25 \pm 3,25$ \\
MOTILE & $26,00 \pm 13,67$ & $41,67 \pm 18,48$ & $38,75 \pm 11,54$ & $36,25 \pm 17,86$ \\
PROGRESSIVE & $16,00 \pm 11,74$ & $27,67 \pm 13,09$ & $25,25 \pm 7,93$ & $26,00 \pm 13,58$ \\
RAPID & $18,75 \pm 13,17$ & $36,33 \pm 17,02$ & $27,75 \pm 8,34$ & $30,00 \pm 16,02$ \\
MEDIUM & $7,25 \pm 1,49$ & $5,33 \pm 2,03$ & $10,75 \pm 5,65$ & $6,25 \pm 3,15$ \\
SLOW & $41,00 \pm 14,26$ & $23,33 \pm 5,36$ & $18,25 \pm 6,05$ & $14,75 \pm 6,20$ \\
STATIC & $33,00 \pm 17,45$ & $34,67 \pm 21,26$ & $43,75 \pm 16,13$ & $48,50 \pm 22,53$ \\
\hline \hline
\end{tabular}

a,b,c: letras diferentes indicam diferença estatística $(p<0,05)$ 
Tabela 5 - Efeitos do tratamento da suplementação de PUFA e Vitamina E nas variáveis de sêmen fresco, de Bos taurus taurus, no tempo 60 (avaliação após 60 dias de tratamento com suplementação de PUFA e Vitamina E) - São Carlos-SP

\begin{tabular}{lcccc} 
& Controle & Vitamina $\mathrm{E}$ & PUFA & PUFA+Vitamina \\
\cline { 2 - 5 } VIVO & $66,00 \pm 11,00$ & $58,67 \pm 17,25$ & $69,25 \pm 11,35$ & $77,25 \pm 8,49$ \\
ACRO & $70,00 \pm 15,00$ & $72,67 \pm 10,93$ & $73,25 \pm 3,47$ & $76,25 \pm 6,26$ \\
DABI & $66,50 \pm 0,50$ & $64,33 \pm 12,33$ & $55,50 \pm 4,35$ & $54,25 \pm 13,12$ \\
DABII & $4,50 \pm 0,50$ & $9,67 \pm 3,33$ & $9,00 \pm 1,22$ & $8,00 \pm 4,74$ \\
DABIII & $5,50 \pm 2,50$ & $5,33 \pm 2,73$ & $5,75 \pm 1,65$ & $3,75 \pm 1,55$ \\
DABIV & $23,50 \pm 1,50$ & $20,67 \pm 9,13$ & $29,75 \pm 3,25$ & $34,00 \pm 16,92$ \\
MDA (mL) & $228,64 \pm 75,30$ & $277,00 \pm 80,17$ & $221,50 \pm 75,45$ & $307,78 \pm 117,13$ \\
MDA (x10 ${ }^{6}$ sptz) & $63,87 \pm 17,70$ & $124,09 \pm 63,80$ & $930,57 \pm 679,39$ & $59,95 \pm 24,02$ \\
SOD & $107,86 \pm 33,20$ & $106,91 \pm 20,26$ & $117,16 \pm 6,76$ & $94,36 \pm 13,73$ \\
GPX & $522,91 \pm 229,98$ & $141,96 \pm 74,92$ & $426,85 \pm 61,43$ & $442,37 \pm 173,79$ \\
DNA & $72,00 \pm 0,50$ & $46,17 \pm 18,78$ & $45,78 \pm 13,06$ & $35,10 \pm 7,09$ \\
VAP & $97,25 \pm 9,95$ & $93,60 \pm 9,01$ & $69,28 \pm 9,21$ & $103,13 \pm 21,83$ \\
VSL & $82,30 \pm 7,90$ & $69,03 \pm 3,85$ & $56,15 \pm 5,87$ & $89,80 \pm 20,15$ \\
VCL & $153,60 \pm 2,70$ & $160,87 \pm 9,70$ & $133,23 \pm 14,38$ & $156,38 \pm 33,09$ \\
ALH & $5,95 \pm 0,25$ & $5,67 \pm 0,75$ & $5,75 \pm 0,69$ & $5,70 \pm 0,81$ \\
BCF & $39,60 \pm 0,30^{\text {ab }}$ & $35,87 \pm 1,05^{\mathrm{b}}$ & $39,38 \pm 1,08^{\mathrm{ab}}$ & $41,13 \pm 1,99^{\mathrm{a}}$ \\
STR & $82,00 \pm 1,00^{\mathrm{ab}}$ & $76,67 \pm 2,67^{\mathrm{b}}$ & $81,00 \pm 3,16^{\mathrm{ab}}$ & $85,75 \pm 1,65^{\mathrm{a}}$ \\
LIN & $54,00 \pm 4,00^{\mathrm{a}}$ & $50,00 \pm 2,52^{\mathrm{bc}}$ & $44,25 \pm 2,21^{\mathrm{c}}$ & $58,50 \pm 2,22^{\mathrm{a}}$ \\
ELONGATION & $44,50 \pm 0,50$ & $43,67 \pm 1,76$ & $41,50 \pm 2,10$ & $46,50 \pm 1,50$ \\
MOTILEPCT & $67,50 \pm 9,50$ & $36,33 \pm 6,89$ & $36,50 \pm 15,70$ & $71,25 \pm 11,08$ \\
PROGRESSIVE & $45,00 \pm 8,00^{\text {ab }}$ & $19,33 \pm 3,33^{\mathrm{b}}$ & $17,50 \pm 8,21^{\mathrm{b}}$ & $53,25 \pm 10,58^{\mathrm{a}}$ \\
RAPID & $56,50 \pm 11,50$ & $26,67 \pm 2,91$ & $25,25 \pm 12,76$ & $61,00 \pm 12,00$ \\
MEDIUM & $11,00 \pm 2,00$ & $10,00 \pm 4,51$ & $11,50 \pm 3,59$ & $10,25 \pm 3,33$ \\
SLOW & $22,50 \pm 0,50$ & $27,33 \pm 3,28$ & $21,50 \pm 5,20$ & $18,25 \pm 6,34$ \\
STATIC & $10,00 \pm 9,00$ & $36,67 \pm 8,69$ & $42,00 \pm 19,51$ & $10,50 \pm 5,52$ \\
\hline \hline
\end{tabular}

a,b,c: letras diferentes indicam diferença estatística $(p<0,05)$

5.3 Efeito da suplementação dos ácidos graxos poliinsaturados (PUFA) e tratamento injetável com Vitamina $\mathrm{E}$ na qualidade dos espermatozoides colhidos da cauda do epidídimo de touros Bos taurus submetidos ao estresse térmico testicular

Abaixo estão apresentados os resultados referentes ao efeito dos tratamentos com PUFA e vitamina E na qualidade dos espermatozoides "in natura" e criopreservados" colhidos da cauda do epidídimo imediatamente após orquiectomia 
bilateral de touros Bos taurus, 75 dias após o início dos tratamentos com PUFA e vitamina $E$.

Observou-se que, no sêmen fresco coletado da cauda do epidídimo dos touros, houve um efeito protetor da vitamina $\mathrm{E}$ na atividade mitocondrial, com as amostras tratadas com esta vitamina apresentando uma menor porcentagem de espermatozoides com nenhuma atividade mitocondrial em relação ao grupo controle (Tabela 6; DAB IV; Vitamina E: 0,83 $\pm 0,48$ vs. Controle: $4,17 \pm 0,95$ ). Da mesma forma, observou-se que uma menor fragmentação de DNA nas amostras tratadas com Vitamina $E$ quando comparadas aos outros grupos (Controle: 42,44 $\pm 7,05^{a}$, Vitamina E: $19,46 \pm 1,46^{\mathrm{b}}$, PUFA: $43,15 \pm 11,93^{\mathrm{a}}$, PUFA e Vitamina E: $53,76 \pm 1,50^{\mathrm{a}}$ ). Tais resultados sugerem um efeito protetor da Vitamina $E$ evitando os efeitos da insulação, principalmente no que diz respeito à espermatogênese.

Por outro lado, as variáveis relacionadas à motilidade avaliadas pelo CASA (e.g., MOTILE, PROGRESSIVE e RAPID) no sêmen fresco coletado da cauda do epidídimo apresentaram valores mais elevados para os animais suplementados com PUFA e Vitamina E (Tabela 6). De fato, esperava-se que a interação entre a suplementação com PUFA e o tratamento com Vitamina $E$ levasse a um aumento nos padrões de motilidade espermática. Os ácidos graxos poli-insaturados por apresentaram uma configuração especial apresentando dobras nas ligações duplas, quando presentes na membrana, levam a uma desestabilização desta membrana (LENZI et al., 1994). Assim, com o aumento na quantidade de ácidos graxos poliinsaturados na membrana espermática, a membrana apresentaria uma maior fluidez, o que permitiria um aumento na motilidade espermática. De fato, estudos indicam que a presença destes ácidos graxos levam a uma melhora na integridade da membrana, na motilidade e viabilidade espermáticas, assim como a uma maior resistência ao choque frio (ROBINSON et al., 2006). Por outro lado, a ligações Carbono-Hidrogênio adjacentes às ligações duplas presentes nos ácidos graxos poli-insaturados são mais sensíveis à clivagem pelas espécies reativas de oxigênio (LANGLAIS; ROBERTS, 1985; LENZI et al., 1994; LADHA, 1998; AITKEN et al., 2006). Desta forma, com a suplementação com PUFAs, esperava-se uma melhora nos padrões de motilidade das amostras. No entanto, com a insulação, esperava-se um aumento na produção de ROS, cujos efeitos deletérios poderiam ser evitados pelo tratamento com Vitamina E, o que foi observado nas amostras frescas epididimárias do presente estudo. 
Visto que, diferente do sêmen ejaculado (coletado até 60 dias da insulação e início do tratamento), houve um efeito benéfico da Vitamina $E$ sobre as amostras coletadas do epidídimo, podemos inferir que, possivelmente, houve um tempo adicional para que a vitamina $E$ atingisse o testículo levando então aos efeitos benéficos observados 75 dias após o tratamento. Possivelmente, se os animais já estivessem sob o tratamento ao menos 15 dias antes da insulação, este tratamento pudesse ser mais efetivo.

Nas amostras coletadas do epidídimo e criopreservadas imediatamente após a coleta, não foram observados efeitos benéficos da Vitamina $\mathrm{E}$. De fato, houve uma menor porcentagem de espermatozoides com alta atividade mitocondrial nas amostras tratadas com Vitamina E (Tabela 7; DAB I; Controle: 61,17 $\pm 4,81^{\text {a }}$, Vitamina $E: 37,80 \pm 11,00^{\mathrm{b}}$; PUFA : $51,67 \pm 7,58^{\mathrm{ab}}$; PUFA e Vitamina $\mathrm{E}: 50,33 \pm$ $6,47^{\mathrm{ab}}$ ). Isto indicaria que os mecanismos relacionados aos danos às mitocôndrias durante a criopreservação poderiam não estar relacionadas diretamente ao estresse oxidativo e sim a um possível dano mecânico causado pela presença de cristais de gelo. Além disto, apesar da ausência de diferenças entre os tratamentos, houve um aumento bastante evidente na fragmentação de DNA nas amostras criopreservadas em comparação as amostras frescas (Tabelas 6 e 7).

De acordo com Sakkas e Alvarez (2010) os danos de DNA espermático podem ocorrer pelos seguintes mecanismos: apoptose abortiva durante o processo de espermatogênese; quebras de fitas de DNA produzidas durante o remodelamento da cromatina espermática durante a espermatogênese; fragmentação de DNA induzida principalmente por espécies reativas de oxigênio durante o trânsito pelos túbulos seminíferos e epidídimo; fragmentação induzida por caspases e endonucleases; danos de DNA causados pela radioterapia e quimioterapia e danos causados por tóxicos ambientais. Pelos resultados encontrados no presente estudo, pode-se incluir entre os possíveis causadores da fragmentação de DNA espermático, a criopreservação. De fato, estudos anteriores relatam que uma das injúrias ao espermatozoide durante a criopreservação seria a fragmentação do DNA (BAUMBER et al., 2003; THOMSON et al., 2009). Inicialmente, poderia se hipotetizar que a fragmentação de DNA durante a insulação escrotal pode estar relacionada tanto a produção excessiva de espécies reativas de oxigênio como pela ativação de caspases e endonucleases. De fato estudos anteriores indicam que a exposição de espermatozoides de camundongos a temperaturas de $40^{\circ} \mathrm{C}$ levam a um aumento 
significativo de fragmentação de DNA espermático (SAILER et al., 1997). Também, Banks et al. (2005) comprovaram a indução de dano ao DNA espermático após exposição in vivo de testículos de camundongos a $42^{\circ} \mathrm{C}$. No entanto, os efeitos das altas temperaturas no DNA espermáticos podem ser observados pouco tempo após a exposição às altas temperaturas. Assim, estes mecanismos estariam mais relacionados aos efeitos agudos da insulação possivelmente durante o trajeto pelo epidídimo. Assim, a fragmentação de DNA observados nos espermatozoides dos touros avaliados no presente estudo nas amostras epididimárias 75 dias após a insulação podem estar relacionadas a um aumento nas falhas de apoptose, sendo que muitas células com DNA lesado escapariam da morte celular, sendo encontradas assim no ejaculado. No entanto, mais estudos são necessários para comprovar esta hipótese.

Tabela 6 - Efeitos do tratamento da suplementação de PUFA e Vitamina E nas variáveis de sêmen fresco, de Bos taurus taurus coletado da cauda do epidídimo imediatamente após castração realizada 75 dias após a insulação e início do tratamento com PUFAs e Vitamina E - São Carlos-SP - 2011

\begin{tabular}{lcccc} 
& Controle & Vitamina E & PUFA & PUFA+Vitamina E \\
\cline { 2 - 5 } VIVO & $84,83 \pm 2,23$ & $80,83 \pm 3,79$ & $82,43 \pm 2,99$ & $81,67 \pm 2,72$ \\
ACRO & $87,67 \pm 3,25$ & $92,83 \pm 1,66$ & $80,14 \pm 7,97$ & $87,67 \pm 2,22$ \\
DABI & $81,17 \pm 2,98$ & $86,00 \pm 2,25$ & $86,57 \pm 2,09$ & $84,00 \pm 2,34$ \\
DABII & $11,83 \pm 1,80$ & $12,50 \pm 2,08$ & $10,00 \pm 1,77$ & $11,33 \pm 1,87$ \\
DABIII & $2,83 \pm 1,11$ & $0,67 \pm 0,21$ & $1,43 \pm 0,65$ & $2,83 \pm 0,98$ \\
DABIV & $4,17 \pm 0,95^{\mathrm{a}}$ & $0,83 \pm 0,48^{\mathrm{b}}$ & $1,57 \pm 0,37^{\mathrm{b}}$ & $1,83 \pm 0,54^{\mathrm{b}}$ \\
MDA (x10 ${ }^{6}$ sptz) & $21,52 \pm 7,20$ & $10,77 \pm 3,28$ & $41,76 \pm 25,99$ & $36,40 \pm 9,43$ \\
SOD & $91,26 \pm 17,69$ & $67,19 \pm 15,54$ & $61,10 \pm 12,63$ & $88,78 \pm 9,01$ \\
GPX & $160,08 \pm 11,51$ & $165,21 \pm 13,71$ & $222,42 \pm 77,19$ & $133,92 \pm 5,34$ \\
DNA & $42,44 \pm 7,05^{\mathrm{a}}$ & $19,46 \pm 1,46^{\mathrm{b}}$ & $43,15 \pm 11,93^{\mathrm{a}}$ & $53,76 \pm 1,50^{\mathrm{a}}$ \\
VAP & $107,27 \pm 10,67^{\mathrm{b}}$ & $110,32 \pm 4,81^{\mathrm{b}}$ & $94,47 \pm 9,60^{\mathrm{b}}$ & $147,57 \pm 2,24^{\mathrm{a}}$ \\
VSL & $68,87 \pm 5,44^{\mathrm{b}}$ & $63,62 \pm 3,59^{\mathrm{b}}$ & $62,50 \pm 5,98^{\mathrm{b}}$ & $117,48 \pm 5,43^{\mathrm{a}}$ \\
VCL & $252,69 \pm 17,04^{\mathrm{ab}}$ & $259,45 \pm 9,59^{\mathrm{a}}$ & $206,47 \pm 18,58^{\mathrm{b}}$ & $251,50 \pm 17,57^{\mathrm{ab}}$ \\
ALH & $9,69 \pm 1,69^{\mathrm{b}}$ & $10,77 \pm 0,60$ & $9,35 \pm 0,95$ & $8,58 \pm 1,00$ \\
BCF & $30,30 \pm 5,12^{\mathrm{b}}$ & $32,80 \pm 1,37^{\mathrm{ab}}$ & $36,60 \pm 1,52^{\mathrm{ab}}$ & $39,80 \pm 1,13^{\mathrm{a}}$ \\
STR & $64,86 \pm 4,27^{\mathrm{b}}$ & $58,33 \pm 1,74^{\mathrm{b}}$ & $66,17 \pm 3,48^{\mathrm{ab}}$ & $78,17 \pm 2,63^{\mathrm{a}}$ \\
LIN $_{\text {ELONGATION }}$ & $28,71 \pm 1,95^{\mathrm{b}}$ & $26,17 \pm 0,65^{\mathrm{b}}$ & $32,67 \pm 3,54^{\mathrm{b}}$ & $49,33 \pm 5,13^{\mathrm{a}}$ \\
MOTILE & $52,00 \pm 1,31^{\mathrm{a}}$ & $48,17 \pm 0,83^{\mathrm{ab}}$ & $42,33 \pm 3,07^{\mathrm{b}}$ & $48,17 \pm 2,26^{\mathrm{ab}}$ \\
PROGRESSIVE & $27,86 \pm 8,85^{\mathrm{b}}$ & $24,67 \pm 6,31^{\mathrm{b}}$ & $46,17 \pm 4,78^{\mathrm{b}}$ & $68,00 \pm 7,88^{\mathrm{a}}$ \\
RAPID & $10,29 \pm 3,48^{\mathrm{b}}$ & $7,83 \pm 2,36^{\mathrm{b}}$ & $17,83 \pm 3,82^{\mathrm{b}}$ & $46,00 \pm 4,20^{\mathrm{a}}$ \\
MEDIUM & $24,71 \pm 7,76^{\mathrm{b}}$ & $22,17 \pm 6,09^{\mathrm{b}}$ & $36,67 \pm 4,92^{\mathrm{b}}$ & $64,50 \pm 8,15^{\mathrm{a}}$ \\
SLOW & $2,86 \pm 1,22^{\mathrm{b}}$ & $2,33 \pm 0,49^{\mathrm{b}}$ & $9,67 \pm 1,58^{\mathrm{a}}$ & $3,67 \pm 0,42^{\mathrm{b}}$ \\
STATIC & $10,86 \pm 3,25^{\mathrm{b}}$ & $11,33 \pm 1,91^{\mathrm{b}}$ & $26,83 \pm 2,41^{\mathrm{a}}$ & $14,00 \pm 2,76^{\mathrm{b}}$ \\
\hline \hline
\end{tabular}

a,b,c: letras diferentes indicam diferença estatística $(p<0,05)$ 
Tabela 7 - Efeitos do tratamento da suplementação de PUFA e Vitamina E nas variáveis de sêmen criopreservado de Bos taurus taurus coletado da cauda do epidídimo imediatamente após castração realizada 75 dias após a insulação e início do tratamento com PUFAs e Vitamina E - São Carlos-SP - 2011

\begin{tabular}{lrrrr} 
& \multicolumn{1}{c}{ Controle } & \multicolumn{1}{c}{ Vitamina } & \multicolumn{1}{c}{ PUFA } & PUFA+Vitamina E \\
\hline VIVO & $65,17 \pm 1,92$ & $66,50 \pm 3,21$ & $61,83 \pm 3,86$ & $55,83 \pm 7,39$ \\
ACRO & $80,00 \pm 1,06$ & $80,00 \pm 1,34$ & $76,33 \pm 3,49$ & $69,33 \pm 9,12$ \\
DABI & $61,17 \pm 4,81^{\mathrm{a}}$ & $37,80 \pm 11,00^{\mathrm{b}}$ & $51,67 \pm 7,58^{\mathrm{ab}}$ & $50,33 \pm 6,47^{\mathrm{ab}}$ \\
DABII & $31,00 \pm 4,69$ & $37,40 \pm 10,80$ & $39,50 \pm 7,08$ & $34,00 \pm 5,41$ \\
DABIII & $5,67 \pm 1,05$ & $4,40 \pm 1,29$ & $4,00 \pm 1,55$ & $8,83 \pm 2,34$ \\
DABIV & $2,17 \pm 0,31$ & $20,40 \pm 19,90$ & $4,83 \pm 2,57$ & $6,83 \pm 1,96$ \\
MDA (x10 ${ }^{\mathrm{b}}$ sptz) & $449,59 \pm 174,65$ & $151,93 \pm 27,15$ & $181,36 \pm 52,22$ & $187,42 \pm 61,34$ \\
DNA & $90,23 \pm 1,10$ & $88,35 \pm 1,25$ & $90,06 \pm 2,27$ & $88,56 \pm 1,02$ \\
VAP & $79,53 \pm 6,29^{\mathrm{a}}$ & $80,32 \pm 9,27^{\mathrm{a}}$ & $58,15 \pm 6,94^{\mathrm{b}}$ & $73,27 \pm 3,89^{\mathrm{ab}}$ \\
VSL & $58,83 \pm 2,85^{\mathrm{ab}}$ & $57,75 \pm 5,15^{\mathrm{ab}}$ & $46,42 \pm 5,71^{\mathrm{b}}$ & $63,25 \pm 2,97^{\mathrm{a}}$ \\
VCL & $165,02 \pm 14,12^{\mathrm{a}}$ & $151,47 \pm 15,92^{\mathrm{ab}}$ & $125,18 \pm 11,60^{\mathrm{b}}$ & $126,88 \pm 8,71^{\mathrm{b}}$ \\
ALH & $7,65 \pm 0,50^{\mathrm{ab}}$ & $8,25 \pm 0,95^{\mathrm{a}}$ & $4,98 \pm 1,23^{\mathrm{c}}$ & $5,30 \pm 0,41^{\mathrm{bc}}$ \\
BCF & $27,70 \pm 1,11^{\mathrm{bc}}$ & $24,58 \pm 2,95^{\mathrm{c}}$ & $30,30 \pm 1,23^{\mathrm{ab}}$ & $35,43 \pm 1,11^{\mathrm{a}}$ \\
STR & $77,17 \pm 3,0^{\mathrm{b}}$ & $75,67 \pm 2,01^{\mathrm{b}}$ & $80,17 \pm 1,74^{\mathrm{b}}$ & $87,67 \pm 1,28^{\mathrm{a}}$ \\
LIN & $40,50 \pm 1,38^{\mathrm{b}}$ & $42,83 \pm 1,89^{\mathrm{b}}$ & $41,50 \pm 2,67^{\mathrm{b}}$ & $56,33 \pm 3,30^{\mathrm{a}}$ \\
ELONGATION & $43,67 \pm 0,99^{\mathrm{a}}$ & $43,17 \pm 0,87^{\mathrm{a}}$ & $36,67 \pm 2,70^{\mathrm{b}}$ & $44,17 \pm 1,19^{\mathrm{a}}$ \\
MOTILEPCT & $18,83 \pm 5,16$ & $10,83 \pm 3,89$ & $11,33 \pm 4,72$ & $18,67 \pm 4,28$ \\
PROGRESSIVE & $9,17 \pm 2,06$ & $5,50 \pm 2,06$ & $5,50 \pm 3,02$ & $11,00 \pm 2,32$ \\
RAPID & $15,33 \pm 4,49$ & $7,00 \pm 2,58$ & $7,33 \pm 3,91$ & $12,33 \pm 2,78$ \\
MEDIUM & $3,67 \pm 0,88$ & $4,00 \pm 1,39$ & $4,00 \pm 1,03$ & $6,17 \pm 1,74$ \\
SLOW & $12,83 \pm 3,57$ & $17,67 \pm 7,80$ & $9,17 \pm 1,35$ & $9,67 \pm 2,43$ \\
STATIC & $68,33 \pm 5,77$ & $71,33 \pm 7,56$ & $79,33 \pm 5,83$ & $71,83 \pm 6,72$ \\
\hline \hline
\end{tabular}

a,b,c: letras diferentes indicam diferença estatística $(p<0,05)$ 


\section{CONCLUSÃO}

Podemos concluir que diferentes espécies reativas de oxigênio apresentam diferentes efeitos sobre espermatozoides provenientes de ejaculados e epidídimos de touros europeus submetidos ao estresse térmico (insulação testicular) e que um tratamento antioxidante direcionado pode ser eficiente para a melhora da qualidade espermática destes animais. No entanto, o tempo para que o tratamento antioxidante atinja o testículo deve ser considerado para que o mesmo seja mais eficiente. 


\section{REFERÊNCIAS}

AGARWAL, A.; IKEMOTO, I.; LOUGHLIN, K. R. Relationship of sperm parameters with levels of reactive oxygen species in semen specimens. Journal Urology, v. 152, n. 1, p. 107-110, 1994.

AITKEN, R. J. A free radical theory of male infertility. Reproduction, Fertility, and Development, v. 6, n. 1, p. 19-23, 1994.

AITKEN, R. J.; WINGATE, J. K.; DE IULIIS, G. N.; KOPPERS, A. J.; MCLAUGHLIN, E. A. Cis-unsaturated fatty acids stimulate reactive oxygen species generation and lipid peroxidation in human spermatozoa. The Journal of Clinical Endocrinology \& Metabolism, v. 91, n. 10, p. 41544163, 2006.

ALEXANDER-NORTH, L. S.; NORTH, J. A.; KIMINYO, K. P.; BUETTNER, G. R.; SPECTOR, A. A. Polyunsaturated fatty acids increase lipid radical formation induced by oxidant stress in endothelial cells. Journal Lipid Reserach, v. 35, n. 10, p. 1773-1785, 1994.

ALVAREZ, J. G.; TOUCHSTONE, J. C.; BLASCO, L.; STOREY, B. T. Spontaneous Lipid peroxidation and production of hydrogen peroxide and superoxide in human spermatozoa superoxide dismutase as major enzyme protectant against oxygen toxicity. Journal of Andrology, v. 8, n. 5, p. 338348, 1987.

ASHES, J.; SIEBERT, B.; GULATI, S.; CUTHBERTSON, A.; SCOTT, T. Incorporation of $n-3$ fatty acids of fish oil into tissue and serum lipids of ruminants. Lipids, v. 27, n. 8, p. 629-631, 1992.

AUSTIN, J.; MURPHREE, R.; HUPP, E. Effect of scrotal insulation on semen of Hereford bulls. Journal of Animal Science, v. 20, n. 2, p. 307, 1961.

BANKS, S.; KING, S. A.; IRVINE, D. S.; SAUNDERS, P. T. K. Impact of a mild scrotal heat stress on DNA integrity in murine spermatozoa.

Reproduction, v. 129, n. 4, p. 505-514, 2005.

BARTH, A.; OKO, R. Abnormal morphology of bovine spermatozoa. Ames: lowa State University Press, 1989.

BAUMBER, J.; BALL, B. A.; LINFOR, J. J.; MEYERS, S. A. Reactive oxygen species and cryopreservation promote dna fragmentation in equine spermatozoa. Journal of Andrology, v. 24, n. 4, p. 621-628, 2003. 
BECONI, M. T.; AFFRANCHINO, M. A.; SCHANG, L. M.; BEORLEGUI, N. B. Influence of antioxidants on SOD activity in bovine sperm. Biochemistry International, v. 23, n. 3, p. 545-553, 1991.

BRINSKO, S. P.; VARNER, D. D.; LOVE, C. C.; BLANCHARD, T. L.; DAY, B. C.; WILSON, M. E. Effect of feeding a DHA-enriched nutriceutical on the quality of fresh, cooled and frozen stallion semen. Theriogenology, v. 63, n. 5, p. 1519-1527, 2005.

CARMELIET, P.; DOR, Y.; HERBERT, J. M.; FUKUMURA, D.; BRUSSELMANS, K.; DEWERCHIN, M.; NEEMAN, M.; BONO, F.; ABRAMOVITCH, R.; MAXWELL, P.; KOCH, C. J.; RATCLIFFE, P.; MOONS, L.; JAIN, R. K.; COLLEN, D.; KESHERT, E. Role of HIF-1alpha in hypoxiamediated apoptosis, cell proliferation and tumour angiogenesis. Nature, v. 394, n. 6692, p. 485-490, 1998.

CHACON, J.; PEREZ, E.; MULLER, E.; SODERQUIST, L.; RODRIGUEZMARTINEZ, $H$. Breeding soundness evaluation of extensively managed bulls in Costa Rica. Theriogenology, v. 52, n. 2, p. 221-231, 1999.

DE LAMIRANDE, E.; JIANG, H.; ZINI, A.; KODAMA, H.; GAGNON, C. Reactive oxygen species and sperm physiology. Reviews Reproduction, v. 2, n. 1, p. 48-54, 1997.

DONNELLY, E. T.; MCCLURE, N.; LEWIS, S. E. Antioxidant supplementation in vitro does not improve human sperm motility. Fertility Sterility, v. 72, n. 3, p. 484-495, 1999.

ERNSTER, L.; FORSMARK, P.; NORDENBRAND, K. The mode of action of lipid-soluble antioxidants in biological membranes: relationship between the effects of ubiquinol and vitamin $E$ as inhibitors of lipid peroxidation in submitochondrial particles. Biofactors, v. 3, n. 4, p. 241-248, 1992.

EVENSON, D. P.; JOST, L. K.; MARSHALL, D.; ZINAMAN, M. J.; CLEGG, E.; PURVIS, K.; DE ANGELIS, P.; CLAUSSEN, O. P. Utility of the sperm chromatin structure assay as a diagnostic and prognostic tool in the human fertility clinic. Human Reproduction, v. 14, n. 4, p. 1039-1049, 1999.

FOOTE, R. H. To the editors. Journal of Andrology, v. 21, n. 3, p. 355-355, 2000.

FRAGA, C. G.; MOTCHNIK, P. A.; SHIGENAGA, M. K.; HELBOCK, H. J.; JACOB, R. A.; AMES, B. N. Ascorbic acid protects against endogenous oxidative DNA damage in human sperm. Proceedings of the National Academy of Sciences, v. 88, n. 24, p. 11003-11006, 1991.

FRENOUX, J.-M. R.; PROST, E. D.; BELLEVILLE, J. L.; PROST, J. L. A Polyunsaturated Fatty acid diet lowers blood pressure and improves antioxidant status in spontaneously hypertensive rats. The Journal of Nutrition, v. 131, n. 1, p. 39-45, 2001. 
FRIJTERS, A. C. J.; RAHMAN, M. B.; SCHOUTEN-NOORDMAN, J. W. J.; VANDAELE, L.; VAN SOOM, A. 178 Modelling the effect of elevated testicular temperature of holstein friesian bulls in a moderate climate on rejection rates of ejaculates in semen processing. Reproduction, Fertility and

Development, v. 24, n. 1, p. 201-201, 2011.

GHARAGOZLOO, P.; AITKEN, R. J. The role of sperm oxidative stress in male infertility and the significance of oral antioxidant therapy. Human

Reproduction, v. 26, n. 7, p. 1628-1640, 2011.

HALLIWELL, B. Reactive oxygen species in living systems: source, biochemistry, and role in human disease. American Journal Medicine, v. 91, n. 3C, p. 14S-22S, 1991.

HISHINUMA, M.; SUZUKI, K.; SEKINE, J. Recovery and cryopreservation of sika deer (Cervus nippon) spermatozoa from epididymides stored at $4{ }^{\circ} \mathrm{C}$. Theriogenology, v. 59, n. 3-4, p. 813-820, 2003.

HOU, W.; DONG, Y.; ZHANG, J.; YIN, Z.; WEN, H.; XIONG, L.; LI, W. Hypoxia-induced deacetylation is required for tetraploid differentiation in response to testicular ischemia-reperfusion (IR) injury. Journal of Andrology, v. 33, n. 6, p. 1379-1386, 2012.

HRUDKA, F. Cytochemical and ultracytochemical demonstration of cytochrome $c$ oxidase in spermatozoa and dynamics of its changes accompanying ageing or induced by stress. International Journal of Andrology, v. 10, n. 6, p. 809-828, 1987.

IIDA, T.; MINE, S.; FUJIMOTO, H.; SUZUKI, K.; MINAMI, Y.; TANAKA, Y. Hypoxia-inducible factor-1alpha induces cell cycle arrest of endothelial cells.

Genes Cells, v. 7, n. 2, p. 143-149, 2002.

IKEDA, H.; KIKUCHI, K.; NOGUCHI, J.; TAKEDA, H.; SHIMADA, A.; MIZOKAMI, T.; KANEKO, H. Effect of preincubation of cryopreserved porcine epididymal sperm. Theriogenology, v. 57, n. 4, p. 1309-1318, 2002.

IVELL, R. Lifestyle impact and the biology of the human scrotum.

Reproductive Biology Endocrinology, v. 5, p. 15, 2007.

KAABI, M.; PAZ, P.; ALVAREZ, M.; ANEL, E.; BOIXO, J. C.; ROUISSI, H.; HERRAEZ, P.; ANEL, L. Effect of epididymis handling conditions on the quality of ram spermatozoa recovered post-mortem. Theriogenology, v. 60, n. 7, p. 1249-1259, 2003.

KANTER, M.; AKTAS, C.; ERBOGA, M. Heat stress decreases testicular germ cell proliferation and increases apoptosis in short term: an immunohistochemical and ultrastructural study. Toxicology Industrial Health, v. 29, n. 2, p. 99-113, 2013. 
KUMI-DIAKA, J.; NAGARATNAM, V.; RWUAAN, J. S. Seasonal and agerelated changes in semen quality and testicular morphology of bulls in a tropical environment. Veterinary Record, v. 108, n. 1, p. 13-15, 1981.

LADHA, S. Lipid heterogeneity and membrane fluidity in a highly polarized cell, the mammalian spermatozoon. The Journal of Membrane Biology, $v$. 165, n. 1, p. 1-10, 1998.

LANGLAIS, J.; ROBERTS, K. D. A molecular membrane model of sperm capacitation and the acrosome reaction of mammalian spermatozoa. Gamete Research, v. 12, n. 2, p. 183-224, 1985.

LENZI, A.; PICARDO, M.; GANDINI, L.; LOMBARDO, F.; TERMINALI, O.; PASSI, S.; DONDERO, F. Andrology: Glutathione treatment of dyspermia: effect on the lipoperoxidation process. Human Reproduction, v. 9, n. 11, p. 2044-2050, 1994.

MAILLARD, V.; HOINARD, C.; ARAB, K.; JOURDAN, M.-L.; BOUGNOUX, P.; CHAJĖS, V. Dietary $\beta$-carotene inhibits mammary carcinogenesis in rats depending on dietary $\alpha$-linolenic acid content. British Journal of Nutrition, v. 96, n. 01, p. 18-21, 2006.

MATÉS, J. M. Effects of antioxidant enzymes in the molecular control of reactive oxygen species toxicology. Toxicology, v. 153, n. 1-3, p. 83-104, 2000.

MAYA-SORIANO, M. J.; TABERNER, E.; SABES-ALSINA, M.; PILES, M.; LOPEZ-BEJAR, M. Absence of beneficial effects on rabbit sperm cell cryopreservation by several antioxidant agents. Zygote, v. 22, p. 1-10, 2013.

MAZIERE, C.; CONTE, M. A.; DEGONVILLE, J.; ALI, D.; MAZIERE, J. C. Cellular enrichment with polyunsaturated fatty acids induces an oxidative stress and activates the transcription factors AP1 and NFkappaB.

Biochemical Biophysical Research Communications, v. 265, n. 1, p. 116122, 1999.

MUKAI, K.; NISHIMURA, M.; KIKUCHI, S. Stopped-flow investigation of the reaction of vitamin $C$ with tocopheroxyl radical in aqueous triton $X-100$ micellar solutions. The structure-activity relationship of the regeneration reaction of tocopherol by vitamin C. Journal of Biological Chemistry, v. 266, n. 1, p. 274-278, 1991.

NEWTON, L. D.; KASTELIC, J. P.; WONG, B.; VAN DER HOORN, F.; THUNDATHIL, J. Elevated testicular temperature modulates expression patterns of sperm proteins in Holstein bulls. Molecular Reproduction and Development, v. 76, n. 1, p. 109-118, 2009. 
$\mathrm{NICHI}, \mathrm{M}$. Sistemas de proteção enzimática e níveis de peroxidação espontânea dos lipídios seminais de touros zebuínos e taurinos criados a campo na região de Dourados, MS. 2003. 101 p. Dissertação (Mestrado em Medicina Veterinária)_Faculdade de Medicina Veterinária e Zootecnia, Universidade de São Paulo, São Paulo, 2003.

NICHI, M.; BOLS, P. E. J.; ZUGE, R. M.; BARNABE, V. H.; GOOVAERTS, I. G. F.; BARNABE, R. C.; CORTADA, C. N. M. Seasonal variation in semen quality in Bos indicus and Bos taurus bulls raised under tropical conditions. Theriogenology, v. 66, n. 4, p. 822-828, 2006.

$\mathrm{NICHI}, \mathrm{M}$. Efeito do tratamento com antioxidantes e ácidos graxos poliinsaturados em amostras espermáticas epididimárias de touros. 2009. 120 p. Tese (Doutorado) - Faculdade de Medicina Veterinária e Zootecnia, Universidade de São Paulo, São Paulo, 2009.

OHKAWA, H.; OHISHI, N.; YAGI, K. Assay for lipid peroxides in animal tissues by thiobarbituric acid reaction. Analytical Biochemistry, v. 95, n. 2, p. 351-358, 1979.

OLSZEWSKA-SLONINA, D. Sperm cyropreservation and oxidative damage. What does it mean? Central European Journal Urology, v. 66, n. 1, p. 50$51,2013$.

OURIQUE, G. M.; FINAMOR, I. A.; SACCOL, E. M.; RIFFEL, A. P.; PES, T. S.; GUTIERREZ, K.; GONCALVES, P. B.; BALDISSEROTTO, B.;

PAVANATO, M. A.; BARRETO, K. P. Resveratrol improves sperm motility, prevents lipid peroxidation and enhances antioxidant defences in the testes of hyperthyroid rats. Reproductive Toxicology, v. 37, p. 31-39, 2013.

PACKER, J. E.; SLATER, T.; WILLSON, R. Direct observation of a free radical interaction between vitamin $\mathrm{E}$ and vitamin $\mathrm{C}$. Nature, v. 278, p. 737738, 1979.

PAPPAS, A. C.; ACAMOVIC, T.; SPARKS, N. H. C.; SURAI, P. F.; MCDEVITT, R. M. Effects of supplementing broiler breeder diets with organic selenium and polyunsaturated fatty acids on egg quality during storage.

Poultry Science, v. 84, n. 6, p. 865-874, 2005.

PARKS, J. E.; LYNCH, D. V. Lipid composition and thermotropic phase behavior of boar, bull, stallion, and rooster sperm membranes. Cryobiology, v. 29, n. 2, p. 255-266, 1992.

PAUL, C.; TENG, S.; SAUNDERS, P. T. A single, mild, transient scrotal heat stress causes hypoxia and oxidative stress in mouse testes, which induces germ cell death. Biology Reproduction, v. 80, n. 5, p. 913-919, 2009.

POPE, C. E.; ZHANG, Y. Z.; DRESSER, B. L. A simple staining method for evaluating acrosomal status of cat spermatozoa. Journal of Zoo and Wildlife Medicine, v. 22, n. 1, p. 87-95, 1991. 
REYES, J. G.; FARIAS, J. G.; HENRIQUEZ-OLAVARRIETA, S.; MADRID, E.; PARRAGA, M.; ZEPEDA, A. B.; MORENO, R. D. The hypoxic testicle: physiology and pathophysiology. Oxidative Medicine Cellular Longevity, v. 2012, p. 929285, 2012.

ROBINSON, J. J.; ASHWORTH, C. J.; ROOKE, J. A.; MITCHELL, L. M.; MCEVOY, T. G. Nutrition and fertility in ruminant livestock. Animal Feed Science and Technology, v. 126, n. 3-4, p. 259-276, 2006.

ROCA-RODRIGUEZ, M. M.; GARCIA-ALMEIDA, J. M.; LUPIANEZ-PEREZ, Y.; RICO, J. M.; TOLEDO, M.; ALCAIDE-TORRES, J.; CARDONA, F.; MEDINA, J. A.; TINAHONES, F. J. Effect of a specific supplement enriched with n-3 polyunsaturated fatty acids on markers of inflammation, oxidative stress and metabolic status of ear, nose and throat cancer patients.

Oncology Reports, v. 31, n. 1, p. 405-414, 2014.

SAILER, B. L.; SARKAR, L. J.; BJORDAHL, J. A.; JOST, L. K.; EVENSON, D. $P$. Effects of Heat Stress on Mouse Testicular Cells and Sperm Chromatin Structure. Journal of Andrology, v. 18, n. 3, p. 294-301, 1997.

SAKKAS, D.; ALVAREZ, J. G. Sperm DNA fragmentation: mechanisms of origin, impact on reproductive outcome, and analysis. Fertility and Sterility, v. 93, n. 4, p. 1027-1036, 2010.

SARIOZKAN, S.; BUCAK, M. N.; TUNCER, P. B.; ULUTAS, P. A.; BILGEN, $A$. The influence of cysteine and taurine on microscopic-oxidative stress parameters and fertilizing ability of bull semen following cryopreservation. Cryobiology, v. 58, n. 2, p. 134-138, 2009.

SHARMA, R. K.; AGARWAL, A. Role of reactive oxygen species in male infertility. Urology, v. 48, n. 6, p. 835-850, 1996.

TAYLOR, L.; MIDGLEY, A. W.; CHRISMAS, B.; MADDEN, L. A.; VINCE, R. V.; MCNAUGHTON, L. R. The effect of acute hypoxia on heat shock protein 72 expression and oxidative stress in vivo. European Journal of Applied Physiology, v. 109, n. 5, p. 849-855, 2010.

THOMSON, L. K.; FLEMING, S. D.; AITKEN, R. J.; DE IULIIS, G. N.; ZIESCHANG, J. A.; CLARK, A. M. Cryopreservation-induced human sperm DNA damage is predominantly mediated by oxidative stress rather than apoptosis. Human Reproduction, v. 24, n. 9, p. 2061-2070, 2009.

THOMSON, L. K.; FLEMING, S. D.; AITKEN, R. J.; DE IULIIS, G. N.; ZIESCHANG, J.-A.; CLARK, A. M. Cryopreservation-induced human sperm DNA damage is predominantly mediated by oxidative stress rather than apoptosis. Human Reproduction, v. 24, n. 9, p. 2061-2070, 2009.

TUNC, O.; THOMPSON, J.; TREMELLEN, K. Improvement in sperm DNA quality using an oral antioxidant therapy. Reproductive Biomedicine Online, v. 18, n. 6, p. 761-768, 2009. 
VOEIKOV, V. L. Reactive oxygen species--(ROS) pathogens or sources of vital energy? Part 1 . ROS in normal and pathologic physiology of living systems. Journal Alternatuve Complementary Medicine, v. 12, n. 2, p. 111-118, 2006.

VON SCHACKY, C.; ANGERER, P.; KOTHNY, W.; THEISEN, K.; MUDRA, H. The Effect of dietary $\omega-3$ fatty acids on coronary atherosclerosisa randomized, double-blind, placebo-controlled trial. Annals of Internal Medicine, v. 130, n. 7, p. 554-562, 1999.

YU, I.; LEIBO, S. P. Recovery of motile, membrane-intact spermatozoa from canine epididymides stored for 8 days at $4 \& \# \times a 0 ;{ }^{\circ} \mathrm{C}$. Theriogenology, v. 57 , n. 3, p. 1179-1190, 2002.

YUN, J. I.; GONG, S. P.; SONG, Y. H.; LEE, S. T. Effects of combined antioxidant supplementation on human sperm motility and morphology during sperm manipulation in vitro. Fertility Sterility, v. 100, n. 2, p. 373-378, 2013. 